\title{
Factors affecting precipitation formation and precipitation susceptibility of marine stratocumulus with variable above- and below-cloud aerosol concentrations over the Southeast Atlantic
}

\author{
Siddhant Gupta ${ }^{1,2}$, Greg M. McFarquhar ${ }^{1,2}$, Joseph R. O'Brien ${ }^{3}$, Michael R. Poellot ${ }^{3}$, David J. Delene ${ }^{3}$, \\ Rose M. Miller ${ }^{4}$, and Jennifer D. Small Griswold ${ }^{5}$ \\ ${ }^{1}$ Cooperative Institute for Severe and High Impact Weather Research and Operations, \\ University of Oklahoma, Norman, OK, USA \\ ${ }^{2}$ School of Meteorology, University of Oklahoma, Norman, OK, USA \\ ${ }^{3}$ Department of Atmospheric Sciences, University of North Dakota, Grand Forks, ND, USA \\ ${ }^{4}$ Department of Atmospheric Sciences, University of Illinois at Urbana-Champaign, Urbana, IL, USA \\ ${ }^{5}$ Department of Meteorology, University of Hawai'i at Manoa, Honolulu, HI, USA \\ Correspondence: Siddhant Gupta (sid@ou.edu)
}

Received: 11 August 2021 - Discussion started: 9 September 2021

Revised: 26 January 2022 - Accepted: 4 February 2022 - Published: 2 March 2022

\begin{abstract}
Aerosol-cloud-precipitation interactions (ACIs) provide the greatest source of uncertainties in predicting changes in Earth's energy budget due to poor representation of marine stratocumulus and the associated ACIs in climate models. Using in situ data from 329 cloud profiles across 24 research flights from the NASA ObseRvations of Aerosols above CLouds and their intEractionS (ORACLES) field campaign in September 2016, August 2017, and October 2018, it is shown that contact between above-cloud biomass burning aerosols and marine stratocumulus over the Southeast Atlantic Ocean was associated with precipitation suppression and a decrease in the precipitation susceptibility $\left(S_{\mathrm{o}}\right)$ to aerosols. The 173 "contact" profiles with aerosol concentration $\left(N_{\mathrm{a}}\right)$ greater than $500 \mathrm{~cm}^{-3}$ within $100 \mathrm{~m}$ above cloud tops had a $50 \%$ lower precipitation rate $\left(R_{\mathrm{p}}\right)$ and a $20 \%$ lower $S_{\mathrm{o}}$, on average, compared to 156 "separated" profiles with $N_{\mathrm{a}}$ less than $500 \mathrm{~cm}^{-3}$ up to at least $100 \mathrm{~m}$ above cloud tops.

Contact and separated profiles had statistically significant differences in droplet concentration $\left(N_{\mathrm{c}}\right)$ and effective radius $\left(R_{\mathrm{e}}\right)$ (95\% confidence intervals from a two-sample $t$ test are reported). Contact profiles had 84 to $90 \mathrm{~cm}^{-3}$ higher $N_{\mathrm{c}}$ and 1.4 to $1.6 \mu \mathrm{m}$ lower $R_{\mathrm{e}}$ compared to separated profiles. In clean boundary layers (below-cloud $N_{\mathrm{a}}$ less than $350 \mathrm{~cm}^{-3}$ ), contact profiles had 25 to $31 \mathrm{~cm}^{-3}$ higher $N_{\mathrm{c}}$ and 0.2 to $0.5 \mu \mathrm{m}$ lower $R_{\mathrm{e}}$. In polluted boundary layers (below-cloud $N_{\mathrm{a}}$ exceeding $350 \mathrm{~cm}^{-3}$ ), contact profiles had 98 to $108 \mathrm{~cm}^{-3}$ higher $N_{\mathrm{c}}$ and 1.6 to $1.8 \mu \mathrm{m}$ lower $R_{\mathrm{e}}$. On the other hand, contact and separated profiles had statistically insignificant differences between the average liquid water path, cloud thickness, and meteorological parameters like surface temperature, lower tropospheric stability, and estimated inversion strength. These results suggest the changes in cloud microphysical properties were driven by ACIs rather than meteorological effects, and adjustments to existing relationships between $R_{\mathrm{p}}$ and $N_{\mathrm{c}}$ in model parameterizations should be considered to account for the role of ACIs.
\end{abstract}




\section{Introduction}

Clouds drive the global hydrological cycle with an annual average precipitation rate of $3 \mathrm{~mm} \mathrm{~d}^{-1}$ over the oceans (Behrangi et al., 2014). Marine stratocumulus cloud (MSC) is the most common cloud type with an annual coverage of $22 \%$ over the ocean surface (Eastman et al., 2011). These low-level, boundary layer clouds typically exist over subtropical oceans in regions with large-scale subsidence such as the Southeast Atlantic Ocean (Klein and Hartmann, 1993). MSCs have higher reflectivity (albedo) than the ocean surface, which results in a strong, negative shortwave cloud radiative forcing (CRF) with a weak and positive longwave CRF (Oreopoulos and Rossow, 2011).

Low-cloud cover in the subsidence regions is negatively correlated with sea surface temperature (SST) (Eastman et al., 2011; Wood and Hartmann, 2006). CRF is thus sensitive to changes in SST, but there is a large spread in model estimates of CRF sensitivity (Bony and Dufresne, 2005). This provides uncertainty in the model estimates of Earth's energy budget in future climate scenarios (Trenberth and Fasullo, 2009). Uncertainty in the parameterization of boundary layer aerosol, cloud, and precipitation processes contributes to model uncertainties (Ahlgrimm and Forbes, 2014; Stephens et al., 2010).

MSC CRF is regulated by cloud processes that depend on cloud microphysical properties, like droplet concentration $\left(N_{\mathrm{c}}\right)$, effective radius $\left(R_{\mathrm{e}}\right)$, and liquid water content (LWC), and macrophysical properties, like cloud thickness $(H)$ and liquid water path (LWP). These cloud properties can depend on the concentration, composition, and size distributions of aerosols, which act as cloud condensation nuclei. Under conditions of constant LWC, increases in aerosol concentration $\left(N_{\mathrm{a}}\right)$ can increase $N_{\mathrm{c}}$ and decrease $R_{\mathrm{e}}$, strengthening the shortwave CRF (Twomey, 1974, 1977). A decrease in droplet sizes in polluted clouds can inhibit droplet growth from collision-coalescence and suppress precipitation intensity, resulting in lower precipitation rate $\left(R_{\mathrm{p}}\right)$, higher LWP, and increased cloud lifetime (Albrecht, 1989). In combination, these aerosol-cloud-precipitation interactions (ACIs) and the resulting cloud adjustments lead to an effective radiative forcing, termed $\mathrm{ERF}_{\mathrm{aci}}$ (Boucher et al., 2013).

Satellite retrievals of $R_{\mathrm{e}}$ and cloud optical thickness $(\tau)$ can be used to estimate $N_{\mathrm{c}}$ and LWP using the adiabatic assumption (Boers et al., 2006; Wood and Hartmann, 2006; Bennartz, 2007). LWC increases linearly with height in adiabatic clouds, and $\tau$ is parameterized as a function of $N_{\mathrm{c}}$ and LWP $\left(\tau \alpha N_{\mathrm{c}}^{1 / 3} \mathrm{LWP}^{5 / 6}\right.$ ) (Brenguier et al., 2000). Since $\tau$ has greater sensitivity to LWP compared to $N_{\mathfrak{c}}$, assuming constant LWP under different aerosol conditions can lead to underestimation of the cloud albedo susceptibility to aerosol perturbations (Platnick and Twomey, 1994; McComiskey and Feingold, 2012).

LWP can have a positive or negative response to increasing $N_{\mathrm{c}}$ due to aerosols (Toll et al., 2019). The LWP response is regulated by environmental conditions (e.g., lower tropospheric stability (LTS), boundary layer depth $\left(H_{\mathrm{BL}}\right)$, and relative humidity), cloud particle sizes (e.g., represented by $R_{\mathrm{e}}$ ), $R_{\mathrm{p}}$, and by $N_{\mathrm{c}}$ and LWP themselves (Chen et al., 2014; Gryspeerdt et al., 2019; Toll et al., 2019; Possner et al., 2020). Accurate estimation of the LWP response to aerosol perturbations is important for regional and global estimates of $\mathrm{ERF}_{\text {aci }}$ (Douglas and L'Ecuyer, 2019, 2020).

Droplet evaporation associated with cloud-top entrainment and precipitation constitutes the two major sinks of LWC in MSC. Smaller droplets associated with higher $N_{\mathrm{c}}$ or $N_{\mathrm{a}}$ evaporate more readily, which leads to greater cloud-top evaporative cooling and a negative LWP response (Hill et al., 2008). The LWP response to the evaporation-entrainment feedback (Xue and Feingold, 2006; Small et al., 2009) also depends on above-cloud humidity (Ackerman et al., 2004). Precipitation susceptibility $\left(S_{\mathrm{o}}\right)$ to aerosol-induced changes in cloud properties is related to the change in $R_{\mathrm{p}}$ due to aerosol-induced changes in $N_{\mathrm{c}}$ and is a function of LWP or $H$ (Feingold and Seibert, 2009).

The magnitude of $S_{\mathrm{o}}$ depends on precipitation formation processes like collision-coalescence which are parameterized in models using mass transfer rates, such as the autoconversion rate $\left(S_{\mathrm{AUTO}}\right)$ and the accretion rate $\left(S_{\mathrm{ACC}}\right)$ (Morrison and Gettelman, 2008; Geoffroy et al., 2010). Autoconversion describes the process of collisions between cloud droplets that coalesce to form drizzle drops which initiate precipitation. Accretion refers to collisions between cloud droplets and drizzle drops which lead to larger drizzle drops and greater precipitation intensity. The variability in $S_{\mathrm{o}}$ as a function of LWP or $H$ depends on the cloud type and the ratio of $S_{\mathrm{ACC}}$ versus $S_{\mathrm{AUTO}}$ (Wood et al., 2009; Jiang et al., 2010; Sorooshian et al., 2010).

Recent field campaigns focused on studying ACIs over the Southeast Atlantic Ocean because unique meteorological conditions are present in the region (Zuidema et al., 2016; Redemann et al., 2021). Biomass burning aerosols from southern Africa are lofted into the free troposphere (Gui et al., 2021) and transported over the Southeast Atlantic by mid-tropospheric winds where the aerosols overlay an extensive MSC deck that exists off the coast of Namibia and Angola (Adebiyi and Zuidema, 2016; Devasthale and Thomas, 2011). The above-cloud aerosol plume is associated with elevated water vapor content (Pistone et al., 2021), which influences cloud-top humidity and dynamics following the mechanisms discussed by Ackerman et al. (2004). In situ observations of cloud and aerosol properties were collected over the Southeast Atlantic during the NASA ObseRvations of Aerosols above CLouds and their intEractionS (ORACLES) field campaign during three Intensive Observation Periods (IOPs) in September 2016, August 2017, and October 2018 (Redemann et al., 2021).

During ORACLES, the aerosol layer was comprised of shortwave-absorbing aerosols $(500 \mathrm{~nm}$ single-scattering albedo of about 0.83 ), with above-cloud aerosol optical depth 
up to 0.42 (Pistone et al., 2019; LeBlanc et al., 2020). The sign of the forcing due to shortwave absorption by the aerosol layer depends on the location of aerosols in the vertical column and the albedo of the underlying clouds (Cochrane et al., 2019). Warming aloft due to aerosol absorption of solar radiation strengthens the temperature inversion, which decreases dry air entrainment into clouds, increases LWP and cloud albedo, and decreases the shortwave CRF (Wilcox, 2010). The net radiative forcing due to the aerosol and cloud layers thus depends on aerosol-induced changes in $N_{\mathrm{c}}, R_{\mathrm{e}}$, and LWP and the resulting changes in $\tau$. Sinks of $N_{\mathrm{c}}$ and LWP like precipitation and entrainment mixing lead to uncertainties in satellite retrievals of $N_{\mathrm{c}}$, which pose the biggest challenge in the use of satellite retrievals to study the aerosol impact on $N_{\mathrm{c}}$ (Quaas et al., 2020). This motivates observational studies of ACIs that examine $N_{\mathrm{c}}$ and LWP under different aerosol and meteorological conditions.

During the 2016 IOP, variable vertical displacement (0 to $2000 \mathrm{~m}$ ) was observed between above-cloud aerosols and the MSC (Gupta et al., 2021; hereafter G21). Instances of contact and separation between the aerosol and cloud layers were associated with differences in the above- and below-cloud $N_{\mathrm{a}}$, water vapor mixing ratio $\left(w_{\mathrm{v}}\right)$, and cloud-top entrainment processes. These differences led to changes in $N_{\mathrm{c}}, R_{\mathrm{e}}$, and LWC and their vertical profiles (G21). In this study, the response of the MSC to above- and below-cloud aerosols is further examined using data from all three ORACLES IOPs, and precipitation formation and $S_{\mathrm{O}}$ are evaluated as a function of $H$.

The paper is organized as follows. In Sect. 2, the ORACLES observations are discussed, along with the data quality assurance procedures (additional details are in the Supplement). In Sect. 3, the calculation of cloud properties is described. In Sect. 4, the influence of aerosols on $N_{\mathrm{c}}, R_{\mathrm{e}}$, and LWC is examined by comparing the parameters for MSC in contact or separated from the above-cloud aerosol layer. In Sect. 5, the changes in precipitation formation due to aerosolinduced microphysical changes are examined. In Sect. 6, $N_{\mathrm{c}}$, $R_{\mathrm{p}}$, and $S_{\mathrm{o}}$ are examined as a function of $H$ and the aboveand below-cloud $N_{\mathrm{a}}$. In Sect. 7, the meteorological conditions are examined using reanalysis data. In Sect. 8, the conclusions are summarized with directions for future work.

\section{Observations}

The ORACLES IOPs were based at Walvis Bay, Namibia $\left(23^{\circ} \mathrm{S}, 14.6^{\circ} \mathrm{E}\right)$, in September 2016, and at São Tomé and Príncipe $\left(0.3^{\circ} \mathrm{N}, 6.7^{\circ} \mathrm{E}\right)$ in August 2017 and October 2018. The data analyzed in this study were collected during the three IOPs (Table 1 and Fig. 1): six P-3 research flights (PRFs) from 6 to 25 September 2016 with cloud sampling conducted between $1^{\circ} \mathrm{W}$ to $12^{\circ} \mathrm{E}$ and 9 to $20^{\circ} \mathrm{S}$; seven PRFs from 12 to 28 August 2017 with cloud sampling conducted between $8^{\circ} \mathrm{W}$ to $6^{\circ} \mathrm{E}$ and 2 to $15^{\circ} \mathrm{S}$; and $11 \mathrm{PRFs}$ from

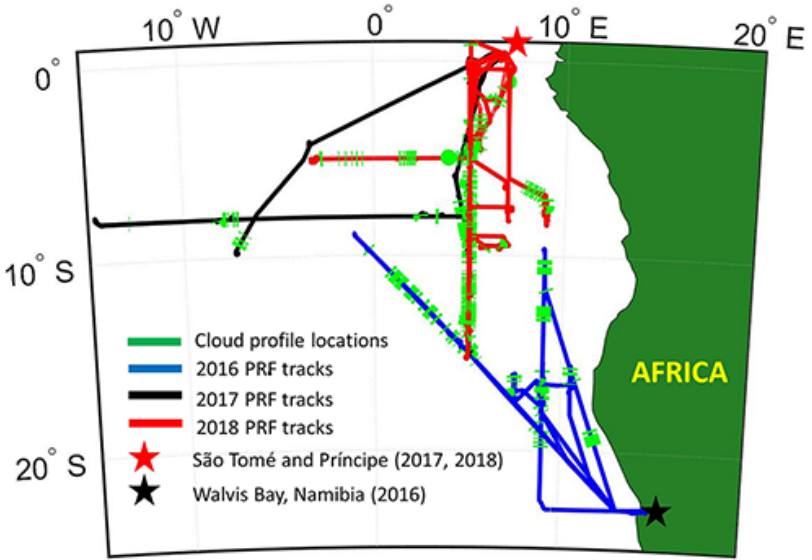

Figure 1. PRF tracks from ORACLES IOPs with base of operations and cloud sampling locations (tracks for multiple 2017 and 2018 PRFs overlap along $5^{\circ} \mathrm{E}$ ).

27 September to 23 October 2018 with cloud sampling conducted between $3^{\circ} \mathrm{W}$ to $9^{\circ} \mathrm{E}$ and $1^{\circ} \mathrm{N}$ to $15^{\circ} \mathrm{S}$. These PRFs were selected because in situ cloud sampling was conducted during at least three vertical profiles through the cloud layer (Table 1).

Three PRFs from the 2016 IOP had overlapping tracks when the P-3B aircraft flew northwest from $23^{\circ} \mathrm{S}, 13.5^{\circ} \mathrm{E}$ toward $10^{\circ} \mathrm{S}, 0^{\circ} \mathrm{E}$ and returned along the same track (Fig. 1). The 2017 and 2018 IOPs had 10 PRFs with overlapping flight tracks when the aircraft flew south from $0^{\circ} \mathrm{N}, 5^{\circ} \mathrm{E}$ toward $15^{\circ} \mathrm{S}, 5^{\circ} \mathrm{E}$ and returned along the same track. PRFs with overlapping tracks acquired statistics for model evaluation (Doherty et al., 2022), while the other PRFs targeted specific locations based on meteorological conditions (Redemann et al., 2021).

During ORACLES, the NASA P-3B aircraft was equipped with in situ probes. The data analyzed in this study were collected using Cloud Droplet Probes (CDPs) (Lance et al., 2010), a cloud and aerosol spectrometer (CAS) on the cloud, aerosol and precipitation spectrometer (Baumgardner et al., 2001), a phase Doppler interferometer (PDI) (Chuang et al., 2008), a two-dimensional stereo probe (2D-S) (Lawson et al., 2006), a high-volume precipitation sampler (HVPS-3) (Lawson et al., 1998), a King hot wire (King et al., 1978), and a Passive Cavity Aerosol Spectrometer Probe (PCASP) (Cai et al., 2013). A single CDP was used during the 2016 IOP (hereafter CDP-A), a second CDP (hereafter CDP-B) was added for the 2017 and 2018 IOPs, and CDP-A was replaced by a different CDP (hereafter CDP-C) for the 2018 IOP.

The CAS, CDP, King hot wire, and PCASP data were processed at the University of North Dakota using the Airborne Data Processing and Analysis processing package (Delene, 2011). The PDI data were processed at the University of Hawaii. The 2D-S and HVPS-3 data were processed using the University of Illinois/Oklahoma Optical Array Probe Pro- 
Table 1. The number of cloud profiles $(n)$ for P-3 research flights (PRFs) analyzed in the study, number of contact and separated profiles with sampling time in parentheses, and instruments that provided valid samples of droplets with $D<50 \mu$ m (instrument used for analysis is in bold).

\begin{tabular}{|c|c|c|c|c|}
\hline PRF number and date & $n$ & Contact & Separated & Instruments \\
\hline PRF05Y16: Sep 6 & 24 & $13(857 \mathrm{~s})$ & $11(470 s)$ & CAS, PDI \\
\hline PRF07Y16: Sep 10 & 9 & $0(0 \mathrm{~s})$ & $9(461 s)$ & CAS, PDI \\
\hline PRF08Y16: Sep 12 & 8 & $1(32 s)$ & $7(472 s)$ & CAS, PDI \\
\hline PRF09Y16: Sep 14 & 8 & $0(0 \mathrm{~s})$ & $8(574 s)$ & CAS, PDI \\
\hline PRF11Y16: Sep 20 & 13 & $13(669 \mathrm{~s})$ & $0(0 \mathrm{~s})$ & CAS, PDI \\
\hline PRF13Y16: Sep 25 & 9 & $3(148 \mathrm{~s})$ & $6(363 \mathrm{~s})$ & CAS, PDI \\
\hline PRF01Y17: Aug 12 & 15 & $14(499 \mathrm{~s})$ & $1(25 \mathrm{~s})$ & CAS, CDP-B \\
\hline PRF02Y17: Aug 13 & 17 & $17(754 \mathrm{~s})$ & $0(0 \mathrm{~s})$ & CAS, CDP-B \\
\hline PRF03Y17: Aug 15 & 12 & $12(272 s)$ & $0(0 s)$ & CAS, CDP-B \\
\hline PRF04Y17: Aug 17 & 7 & $7(127 \mathrm{~s})$ & $0(0 \mathrm{~s})$ & CAS, CDP-B \\
\hline PRF07Y17: Aug 21 & 13 & $9(188 \mathrm{~s})$ & $4(76 s)$ & CAS, CDP-B \\
\hline PRF08Y17: Aug 24 & 9 & $9(324 \mathrm{~s})$ & $0(0 \mathrm{~s})$ & CAS, CDP-B \\
\hline PRF10Y17: Aug 28 & 11 & $7(496 s)$ & $4(168 \mathrm{~s})$ & CAS, CDP-B \\
\hline PRF01Y18: Sep 27 & 21 & $0(0 \mathrm{~s})$ & $21(933 \mathrm{~s})$ & CAS, CDP-B, CDP-C \\
\hline PRF02Y18: Sep 30 & 13 & $7(337 \mathrm{~s})$ & $6(183 s)$ & CAS, CDP-B, CDP-C \\
\hline PRF04Y18: Oct 3 & 5 & $0(0 \mathrm{~s})$ & $5(137 \mathrm{~s})$ & CAS, CDP-B, CDP-C \\
\hline PRF05Y18: Oct 5 & 4 & $4(109 \mathrm{~s})$ & $0(0 \mathrm{~s})$ & CAS, CDP-B, CDP-C \\
\hline PRF06Y18: Oct 7 & 10 & $10(337 \mathrm{~s})$ & $0(0 \mathrm{~s})$ & CAS, CDP-B, CDP-C \\
\hline PRF07Y18: Oct 10 & 13 & $11(472 \mathrm{~s})$ & $2(153 \mathrm{~s})$ & CDP-B, CDP-C \\
\hline PRF08Y18: Oct 12 & 19 & $0(0 \mathrm{~s})$ & $19(773 \mathrm{~s})$ & CDP-B, CDP-C \\
\hline PRF09Y18: Oct 15 & 30 & $17(766 s)$ & $13(365 \mathrm{~s})$ & CDP-B, CDP-C \\
\hline PRF11Y18: Oct 19 & 12 & $0(0 \mathrm{~s})$ & $12(731 s)$ & CDP-B, CDP-C \\
\hline PRF12Y18: Oct 21 & 18 & $0(0 \mathrm{~s})$ & $18(833 \mathrm{~s})$ & CDP-B, CDP-C \\
\hline PRF13Y18: Oct 23 & 29 & $19(777 \mathrm{~s})$ & $10(366 \mathrm{~s})$ & CDP-B, CDP-C \\
\hline Total (2016) & 71 & $30(1706 s)$ & $41(2340 s)$ & \\
\hline Total (2017) & 84 & $75(2660 s)$ & $9(269 s)$ & \\
\hline Total (2018) & 174 & $68(2798 s)$ & $106(4474 s)$ & \\
\hline Total & 329 & $173(7164 s)$ & $156(7083 s)$ & \\
\hline
\end{tabular}

cessing Software (McFarquhar et al., 2018). The data processing procedures followed to reject artifacts were summarized by G21. Comparisons between the cloud probe datasets are described in the Supplement.

The King hot wire was used to sample LWC (hereafter King LWC). The PCASP was used to sample the accumulation-mode aerosols sized from 0.1 to $3.0 \mu \mathrm{m}$. The CAS, CDP, PDI, 2D-S, and HVPS-3 collectively sampled the number distribution function $N(D)$ for particles with diameter $D$ from 0.5 to $19200 \mu \mathrm{m}$. The size distribution covering the complete droplet size range was determined by merging the $N(D)$ for $3<D<50 \mu \mathrm{m}$ with the $N(D)$ for $50<D<1050 \mu \mathrm{m}$ from the 2D-S and the $N(D)$ for $1050<D<19200 \mu \mathrm{m}$ from the HVPS-3. The HVPS-3 sampled droplets with $D>1050 \mu \mathrm{m}$ for a single $1 \mathrm{~Hz}$ data sample across the PRFs analyzed in this study. Measurement uncertainties in droplet sizes were expected to be within $20 \%$ for droplets with $D>5 \mu \mathrm{m}$ from the CAS and the CDP, $D>50 \mu \mathrm{m}$ from the 2D-S, and $D>750 \mu \mathrm{m}$ from the HVPS-3 (Baumgardner et al., 2017).
During each PRF, at least two independent measurements of $N(D)$ were made for $3<D<50 \mu \mathrm{m}$ using the CAS, the PDI, or a CDP (Table 1). The differences between the $N_{\mathrm{c}}$ and LWC derived from the CAS, PDI, and CDP $N(D)$ were quantified to determine if these differences were within measurement uncertainties. The LWC estimates from the CAS, PDI, and CDP were compared with the adiabatic LWC $\left(\mathrm{LWC}_{\mathrm{ad}}\right)$, which represents the theoretical maximum for LWC (Brenguier et al., 2000). The $N(D)$ for droplets with $D<50 \mu \mathrm{m}$ was determined using the probe which consistently had the LWC with better agreement with the $\mathrm{LWC}_{\mathrm{ad}}$ during each IOP (see Supplement). $\mathrm{LWC}_{\mathrm{ad}}$ can be used to compare LWC from different probes since it is derived using environmental conditions and does not depend on the cloud probe datasets. The relative differences between the $\mathrm{LWC}_{\mathrm{ad}}$ and the LWC estimates from cloud probes provide a measure of the uncertainty associated with using one probe over the other for data analysis.

The differences between in-cloud datasets from different instruments were determined using a two-sample $t$ test. The $95 \%$ confidence intervals (CIs) between parameter means 
were reported if the differences were statistically significant. During the 2017 IOP, the CAS and the CDP-B sampled droplets with $D<50 \mu \mathrm{m}$. The CDP-B LWC was higher than the CAS LWC (95\% CIs: 0.11 to $0.12 \mathrm{~g} \mathrm{~m}^{-3}$ higher), and the average CDP-B LWC $\left(0.18 \mathrm{~g} \mathrm{~m}^{-3}\right)$ had better agreement with the average $\mathrm{LWC}_{\mathrm{ad}}\left(0.24 \mathrm{~g} \mathrm{~m}^{-3}\right)$ compared to the average CAS LWC $\left(0.08 \mathrm{~g} \mathrm{~m}^{-3}\right)$. Thus, the CDP-B $N(D)$ was used to represent the $N(D)$ for droplets with $D<50 \mu \mathrm{m}$ for the 2017 IOP.

Similar results were obtained when the CAS LWC and the CDP-B LWC were compared with the $\mathrm{LWC}_{\mathrm{ad}}$ for the 2018 IOP. During the 2018 IOP, the CDP-C was mounted at a different location relative to the aircraft wing compared to the CAS and CDP-B, and the positions of CDP-B and CDP-C were switched after 10 October 2018. O'Brien et al. (2022) found the CDP mounting positions had only a $6 \%$ impact on the calculation of $N_{\mathrm{c}}$, and the average CDP-B LWC and CDP-C LWC were within $0.02 \mathrm{~g} \mathrm{~m}^{-3}$. To maintain consistency with the 2017 IOP, data from the CDP mounted next to the CAS were used for droplets with $D<50 \mu \mathrm{m}$ for the 2018 IOP (except on 15 October 2018 when the CDP-C had a voltage issue).

During the 2016 IOP, measurements from the CDP-A were unusable for all PRFs due to an optical misalignment issue. Nevertheless, the CAS and the PDI sampled droplets with $3<D<50 \mu \mathrm{m}$. On average, the PDI LWC was higher than the CAS LWC (95\% CIs: 0.20 to $0.21 \mathrm{~g} \mathrm{~m}^{-3}$ higher). Since the PDI LWC was greater than the $\mathrm{LWC}_{\mathrm{ad}}(95 \%$ CIs: 0.04 to $0.06 \mathrm{~g} \mathrm{~m}^{-3}$ higher), it was hypothesized that the PDI LWC was an overestimate of the actual LWC. Thus, the CAS $N(D)$ was used to represent the $N(D)$ for droplets with $D<50 \mu \mathrm{m}$ for the 2016 IOP.

The 2D-S has two channels which concurrently sample the cloud volume. $N_{\mathrm{c}}$ and LWC were derived using data from the horizontal channel $\left(N_{\mathrm{H}}\right.$ and $\left.\mathrm{LWC}_{\mathrm{H}}\right)$ and the vertical channel $\left(N_{\mathrm{V}}\right.$ and $\left.\mathrm{LWC}_{\mathrm{V}}\right) . N_{\mathrm{H}}$ and $\mathrm{LWC}_{\mathrm{H}}$ were used for the 2016 IOP because $N_{\mathrm{V}}$ and $\mathrm{LWC}_{\mathrm{V}}$ were not available due to soot deposition on the inside of the receive-side mirror of the vertical channel. $N_{\mathrm{H}}$ and $N_{\mathrm{V}}$ as well as $\mathrm{LWC}_{\mathrm{H}}$ and $\mathrm{LWC}_{\mathrm{V}}$ were strongly correlated for the 2017 and 2018 IOPs, with Pearson's correlation coefficient $R \geq 0.92$ and the best-fit slope $\geq 0.90$. The high correlation values suggest that little difference would have resulted from using the average of the two 2D-S channels. To maintain consistency with the $2016 \mathrm{IOP}, N_{\mathrm{H}}$ and $\mathrm{LWC}_{\mathrm{H}}$ were used for all three IOPs.

\section{Cloud properties}

The $N(D)$ from the merged droplet size distribution was integrated to calculate $N_{\mathrm{c}}$. The $1 \mathrm{~Hz}$ data samples with $N_{\mathrm{c}}>10 \mathrm{~cm}^{-3}$ and King LWC $>0.05 \mathrm{~g} \mathrm{~m}^{-3}$ were defined as in-cloud measurements $(\mathrm{G} 21)$. The PCASP $N(D)$ was used to determine the out-of-cloud $N_{\mathrm{a}}$. In situ cloud sampling during ORACLES included flight legs when the P-3B aircraft as- cended or descended through the cloud layer (hereafter cloud profiles). Data from 329 cloud profiles with just under $4 \mathrm{~h}$ of cloud sampling were examined (Table 1).

For every cloud profile, the cloud top height $\left(Z_{\mathrm{T}}\right)$ was defined as the highest altitude with $N_{\mathrm{c}}>10 \mathrm{~cm}^{-3}$ and King LWC $>0.05 \mathrm{~g} \mathrm{~m}^{-3}$ (Table 2). The average $Z_{\mathrm{T}}$ during ORACLES was $1038 \pm 270 \mathrm{~m}$, where the uncertainty estimate refers to the standard deviation. The cloud base height $\left(Z_{\mathrm{B}}\right)$ was defined as the lowest altitude with $N_{\mathrm{c}}>10 \mathrm{~cm}^{-3}$ and King LWC $>0.05 \mathrm{~g} \mathrm{~m}^{-3}$. In decoupled boundary layers, a layer of cumulus can be present below the stratocumulus layer with a gap between the cloud layers (Wood, 2012). Measurements from stratocumulus were used in this study, and $Z_{\mathrm{B}}$ for the stratocumulus layer was identified as the altitude above which the King LWC increased without gaps greater than $25 \mathrm{~m}$ in the cloud sampling up to $Z_{\mathrm{T}}$.

The difference between $Z_{\mathrm{T}}$ and $Z_{\mathrm{B}}$ was defined as $H$. Due to aerosol-induced changes in entrainment and boundary layer stability, the aerosol impact on $H$ and $Z_{\mathrm{T}}$ can have the strongest influence on LWP adjustments associated with ACIs (Toll et al., 2019). Thus, the influence of ACIs on precipitation formation and $S_{0}$ was examined as a function of $H$. Data collected during incomplete profiles of the stratocumulus or while sampling open-cell clouds (for example, on 2 October 2018) were excluded because of difficulties with estimating $H$ for such profiles.

For each $1 \mathrm{~Hz}$ in-cloud data sample, the droplet size distribution was used to calculate $R_{\mathrm{e}}$ following Hansen and Travis (1974), where

$R_{\mathrm{e}}(h)=\int_{3}^{\infty} D^{3} N(D, h) \mathrm{d} D / \int_{3}^{\infty} 2 D^{2} N(D, h) \mathrm{d} D$.

Based on the aircraft speed, $1 \mathrm{~Hz}$ data samples corresponded to roughly $5 \mathrm{~m}$ intervals in the vertical direction. LWC was calculated as

$\operatorname{LWC}(h)=\pi \rho_{w} / 6 \int_{3}^{\infty} D^{3} N(D, h) \mathrm{d} D$,

where $\rho_{w}$ is the density of liquid water, and $h$ is height in cloud above cloud base. LWC and King LWC were integrated over $h$ from $Z_{\mathrm{B}}$ to $Z_{\mathrm{T}}$ to calculate LWP and King LWP, respectively. $\tau$ was calculated as

$\beta_{\text {ext }}(h)=\int_{3}^{\infty} Q_{\text {ext }} \pi / 4 D^{2} N(D, h) \mathrm{d} D$,

$\tau=\int_{Z_{\mathrm{B}}}^{Z_{\mathrm{T}}} \beta_{\mathrm{ext}}(h) \mathrm{d} h$,

where $\beta_{\text {ext }}$ is the cloud extinction, and $Q_{\text {ext }}$ is the extinction coefficient (approximately 2 for cloud droplets, assuming geometric optics apply for visible wavelengths) (Hansen and 
Table 2. Range of time, latitude, longitude, $Z_{\mathrm{T}}$, and cloud top pressure $\left(P_{\mathrm{T}}\right)$ for PRFs in Table 1.

\begin{tabular}{lrrrrr}
\hline PRF & Time $(\mathrm{UTC})$ & Latitude $\left({ }^{\circ} \mathrm{S}\right)$ & Longitude $\left({ }^{\circ} \mathrm{E}\right)$ & $Z_{\mathrm{T}}(\mathrm{m})$ & $P_{\mathrm{T}}(\mathrm{mb})$ \\
\hline PRF05Y16: Sep 6 & $08: 46-12: 35$ & $10.2-19.7$ & $9.00-11.9$ & $359-1002$ & $904-976$ \\
PRF07Y16: Sep 10 & $09: 09-12: 36$ & $14.1-18.7$ & $4.00-8.60$ & $990-1201$ & $885-908$ \\
PRF08Y16: Sep 12 & $11: 16-12: 26$ & $9.70-12.9$ & $-0.30-3.00$ & $1146-1226$ & $881-890$ \\
PRF09Y16: Sep 14 & $09: 36-14: 16$ & $16.4-18.1$ & $7.50-9.00$ & $635-824$ & $922-945$ \\
PRF11Y16: Sep 20 & $08: 44-13: 11$ & $15.7-17.3$ & $8.90-10.5$ & $432-636$ & $941-966$ \\
PRF13Y16: Sep 25 & $10: 59-13: 51$ & $10.9-14.3$ & $0.80-4.30$ & $729-1124$ & $890-934$ \\
PRF01Y17: Aug 12 & $11: 30-15: 01$ & $2.41-13.0$ & $4.84-5.13$ & $748-1379$ & $866-933$ \\
PRF02Y17: Aug 13 & $10: 15-13: 07$ & $7.20-9.00$ & $4.50-5.00$ & $779-1384$ & $865-928$ \\
PRF03Y17: Aug 15 & $11: 26-13.32$ & $9.08-15.0$ & $4.96-5.00$ & $536-1148$ & $887-954$ \\
PRF04Y17: Aug 17 & $12: 03-16: 14$ & $7.99-9.43$ & -7.0 to-12.8 & $1547-1782$ & $827-848$ \\
PRF07Y17: Aug 21 & $13: 20-16: 37$ & $7.96-8.05$ & $-8.16-3.32$ & $1061-1491$ & $855-897$ \\
PRF08Y17: Aug 24 & $11: 28-14: 58$ & $4.90-14.8$ & $4.97-5.15$ & $911-2015$ & $801-916$ \\
PRF10Y17: Aug 28 & $11: 46-13: 18$ & $7.84-11.0$ & $4.89-5.01$ & $1070-1216$ & $881-897$ \\
PRF01Y18: Sep 27 & $10: 07-13: 11$ & $5.66-12.1$ & $4.87-5.03$ & $819-1169$ & $885-922$ \\
PRF02Y18: Sep 30 & $09: 50-12: 24$ & $6.85-8.18$ & $4.94-5.13$ & $747-840$ & $920-930$ \\
PRF04Y18: Oct 3 & $13: 17-14: 41$ & $-1.05-4.61$ & $5.00-5.06$ & $1137-2151$ & $790-888$ \\
PRF05Y18: Oct 5 & $07: 22-10: 09$ & $9.50-9.63$ & $5.79-6.66$ & $780-892$ & $915-928$ \\
PRF06Y18: Oct 7 & $11: 04-11: 29$ & $10.1-11.8$ & $5.00-5.00$ & $863-928$ & $913-918$ \\
PRF07Y18: Oct 10 & $10: 16-13: 31$ & $4.46-13.1$ & $4.88-5.09$ & $926-1329$ & $866-912$ \\
PRF08Y18: Oct 12 & $13: 02-16: 19$ & $1.02-4.58$ & $5.50-6.96$ & $1073-1905$ & $813-895$ \\
PRF09Y18: Oct 15 & $10: 27-13: 09$ & $5.25-14.1$ & $4.91-5.00$ & $693-1547$ & $849-937$ \\
PRF11Y18: Oct 19 & $11: 58-13: 00$ & $6.50-7.70$ & $8.00-9.06$ & $701-1276$ & $873-932$ \\
PRF12Y18: Oct 21 & $10: 21-13: 07$ & $4.91-13.5$ & $4.88-5.00$ & $675-983$ & $902-936$ \\
PRF13Y18: Oct 23 & $10: 28-13: 38$ & $3.07-5.00$ & $-2.65-5.00$ & $873-1281$ & $873-915$ \\
\hline
\end{tabular}

Travis, 1974). The integrals in Eqs. (1) to (3) were converted to discrete sums for $D>3 \mu \mathrm{m}$ to consider the contributions of cloud drops and not aerosols.

According to the adiabatic model (Brenguier et al., 2000), $\mathrm{LWC}_{\mathrm{ad}}$ and $\mathrm{LWP}_{\mathrm{ad}}$ are functions of $H$ (the subscript "ad" added to represent the adiabatic equivalents). These relationships help parameterize $\tau_{\mathrm{ad}}$ as

$\mathrm{LWC}_{\mathrm{ad}}(h) \propto h, \mathrm{LWP}_{\mathrm{ad}} \propto H^{2}, \tau_{\mathrm{ad}} \propto\left(N_{\mathrm{c}}\right)^{1 / 3} \mathrm{LWP}^{5 / 6}$.

\section{Aerosol influence on cloud microphysics}

The MSCs over the Southeast Atlantic were overlaid by biomass burning aerosols from southern Africa (Adebiyi and Zuidema, 2016; Redemann et al., 2021), with instances of contact and separation between the MSC cloud tops and the base of the biomass burning aerosol layer (G21). Across the three IOPs, 173 profiles were conducted at locations where an extensive aerosol plume with $N_{\mathrm{a}}>500 \mathrm{~cm}^{-3}$ was located within $100 \mathrm{~m}$ above $Z_{\mathrm{T}}$ (hereafter contact profiles) (Table 1). 156 profiles were conducted at locations where the level of $N_{\mathrm{a}}>500 \mathrm{~cm}^{-3}$ was located at least $100 \mathrm{~m}$ above $Z_{\mathrm{T}}$ (hereafter separated profiles). About $50 \%$ of the in situ cloud sampling across the three IOPs was conducted during contact profiles (Table 1). Due to inter-annual variability, contact profiles accounted for about $42 \%, 91 \%$, and $39 \%$ of the in situ cloud sampling during the 2016, 2017, and 2018 IOPs, respectively.

The average $N_{\mathrm{c}}$ and $R_{\mathrm{e}}$ for all cloud profiles across the three IOPs were $157 \pm 96 \mathrm{~cm}^{-3}$ and $8.2 \pm 2.7 \mu \mathrm{m}$, respectively (Table 3 ). The high proportion of contact profiles during the 2017 IOP was associated with higher average $N_{\mathrm{c}}$ and lower average $R_{\mathrm{e}}\left(229 \mathrm{~cm}^{-3}\right.$ and $\left.6.9 \mu \mathrm{m}\right)$ compared to the 2016 IOP $\left(150 \mathrm{~cm}^{-3}\right.$ and $\left.7.0 \mu \mathrm{m}\right)$ and the $2018 \operatorname{IOP}\left(132 \mathrm{~cm}^{-3}\right.$ and $9.8 \mu \mathrm{m})$. It is possible that the use of CDP-B data for the 2017 IOP contributed to the increase in average $N_{\mathrm{c}}$ relative to the 2016 IOP. However, the difference between the average CAS $N_{\mathrm{c}}$ and the average CDP-B $N_{\mathrm{c}}$ for the 2017 IOP $\left(12 \mathrm{~cm}^{-3}\right)$ was lower than the difference between the average $N_{\mathrm{c}}$ for the 2016 and 2017 IOPs $\left(79 \mathrm{~cm}^{-3}\right)$. The difference between the $N_{\mathrm{c}}$ for these IOPs was thus primarily due to the conditions at the cloud sampling locations. The microphysical differences between the 2016 and 2017 IOPs were associated with differences in surface precipitation. Based on the W-band retrievals from the Jet Propulsion Laboratory Airborne Precipitation Radar Version 3 (APR-3), the 2017 IOP had fewer profiles with precipitation reaching the surface $(13 \%)$ compared to the 2016 IOP (34\%) (Dzambo et al., 2019).

On average, contact profiles had significantly higher $N_{\mathrm{c}}$ (95\% CIs: 84 to $90 \mathrm{~cm}^{-3}$ higher) and lower $R_{\mathrm{e}}(95 \%$ CIs: 1.4 to $1.6 \mu \mathrm{m}$ lower) compared to separated profiles (throughout the study, the term "significant" is exclusively used to represent statistical significance). The significant differences 
Table 3. Average values for cloud properties measured during cloud profiles from the PRFs listed in Table 1 for each IOP. Error estimates represent 1 standard deviation. $R$ between LWP estimates and $H$ in parentheses.

\begin{tabular}{lrrrr}
\hline Parameter & 2016 & 2017 & 2018 & All \\
\hline Profile count & 71 & 84 & 174 & 329 \\
$N_{\mathrm{c}}\left(\mathrm{cm}^{-3}\right)$ & $150 \pm 73$ & $229 \pm 108$ & $132 \pm 87$ & $157 \pm 96$ \\
$R_{\mathrm{e}}(\mu \mathrm{m})$ & $7.0 \pm 1.9$ & $6.9 \pm 1.6$ & $9.8 \pm 3.3$ & $8.2 \pm 2.7$ \\
$\mathrm{LWC}\left(\mathrm{g} \mathrm{m}^{-3}\right)$ & $0.15 \pm 0.09$ & $0.21 \pm 0.15$ & $0.26 \pm 0.17$ & $0.22 \pm 0.16$ \\
King LWC $\left(\mathrm{g} \mathrm{m}^{-3}\right)$ & $0.29 \pm 0.15$ & $0.23 \pm 0.17$ & $0.24 \pm 0.14$ & $0.25 \pm 0.15$ \\
$\tau$ & $7.2 \pm 3.6$ & $7.2 \pm 8.9$ & $9.0 \pm 7.7$ & $8.8 \pm 7.7$ \\
$H(\mathrm{~m})$ & $244 \pm 83$ & $148 \pm 92$ & $212 \pm 116$ & $201 \pm 108$ \\
$\mathrm{LWP}\left(\mathrm{g} \mathrm{m}^{-2}\right)$ & $34 \pm 17(0.75)$ & $37 \pm 43(0.88)$ & $59 \pm 54(0.83)$ & $48 \pm 47(0.78)$ \\
King LWP $\left(\mathrm{g} \mathrm{m}^{-2}\right)$ & $68 \pm 30(0.80)$ & $37 \pm 35(0.84)$ & $52 \pm 40(0.89)$ & $52 \pm 38(0.87)$ \\
$\mathrm{LWP}_{\mathrm{ad}}\left(\mathrm{g} \mathrm{m}^{-2}\right)$ & $77 \pm 57(0.97)$ & $51 \pm 55(0.96)$ & $93 \pm 97(0.94)$ & $79 \pm 82(0.93)$ \\
$R_{\mathrm{p}}\left(\mathrm{mm} \mathrm{h}^{-1}\right)$ & $0.02 \pm 0.05$ & $0.02 \pm 0.08$ & $0.10 \pm 0.33$ & $0.06 \pm 0.25$ \\
\hline
\end{tabular}

in $N_{\mathrm{c}}$ and $R_{\mathrm{e}}$ were associated with significantly higher $\tau$ (95\% CIs: 0.04 to 3.06 higher) for contact profiles, in accordance with the Twomey effect (Twomey, 1974, 1977). These results were consistent with the 2016 IOP when the contact profiles had higher $N_{\mathrm{c}}$ (95\% CIs: 60 to $68 \mathrm{~cm}^{-3}$ higher), lower $R_{\mathrm{e}}$ (95\% CIs: 1.1 to $1.3 \mu \mathrm{m}$ lower), and higher $\tau$ (95\% CIs: 1.1 to 4.3 higher) (G21).

Figure 2 shows violin plots for cloud properties as a function of normalized height $\left(Z_{\mathrm{N}}\right)$, defined as $Z_{\mathrm{N}}=Z-$ $-Z_{\mathrm{B}} / Z_{\mathrm{T}}-Z_{\mathrm{B}}$. The violin plots include box plots and illustrate the distribution of the data (Hintze and Nelson, 1998). The median $N_{\mathrm{c}}$ increased with $Z_{\mathrm{N}}$ for $Z_{\mathrm{N}} \leq 0.25$, consistent with droplet nucleation (Fig. 2a). The median $N_{\mathrm{c}}$ decreased near cloud top for $Z_{\mathrm{N}} \geq 0.75$ from 204 to $154 \mathrm{~cm}^{-3}$ for contact and from 104 to $69 \mathrm{~cm}^{-3}$ for separated profiles. This is consistent with droplet evaporation associated with cloud-top entrainment (G21). The median $R_{\mathrm{e}}$ increased with $Z_{\mathrm{N}}$ consistent with condensational growth (Fig. 2b). There was a greater increase in the median $R_{\mathrm{e}}$ from cloud base to cloud top for separated profiles (from 7.1 to $9.5 \mu \mathrm{m}$ ) compared to contact profiles (from 6.1 to $7.9 \mu \mathrm{m}$ ). This is consistent with previous observations of stronger droplet growth in cleaner conditions as a function of $Z_{\mathrm{N}}$ (Braun et al., 2018; G21) and LWP (Rao et al., 2020). Statistically insignificant differences between the average $H$ for contact and separated profiles suggest that the differential droplet growth was associated with differences in cloud processes like collisioncoalescence (further discussed in Sect. 5).

The LWC and LWP responses to changes in aerosol conditions were examined because the adiabatic model suggests $\tau \alpha \mathrm{LWP}^{5 / 6}$ (Eq. 4) (Brenguier et al., 2000). Contact profiles had significantly higher LWC, but the relative increase was less than $10 \%$ (Table 4). LWC was divided into rainwater content (RWC) and cloud water content (CWC) based on droplet size. Droplets with $D>50 \mu \mathrm{m}$ were defined as drizzle (Abel and Boutle, 2012; Boutle et al., 2014), and the total drizzle mass was defined as RWC. The droplet mass (a)

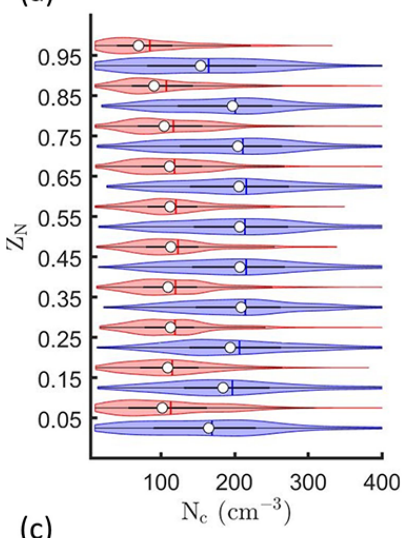

(c)

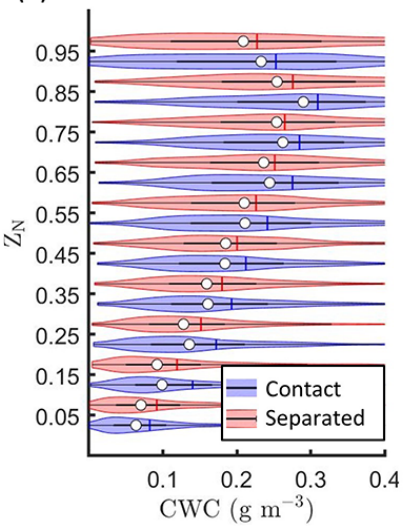

(b)

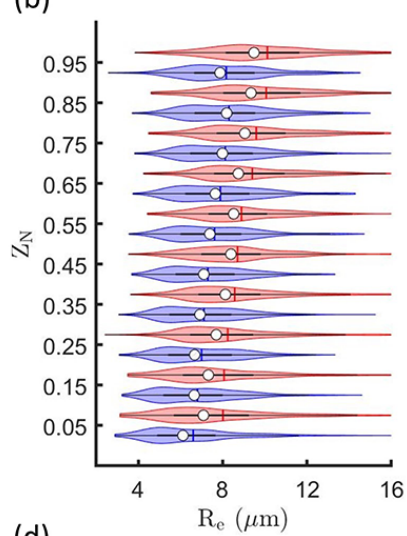

(d)

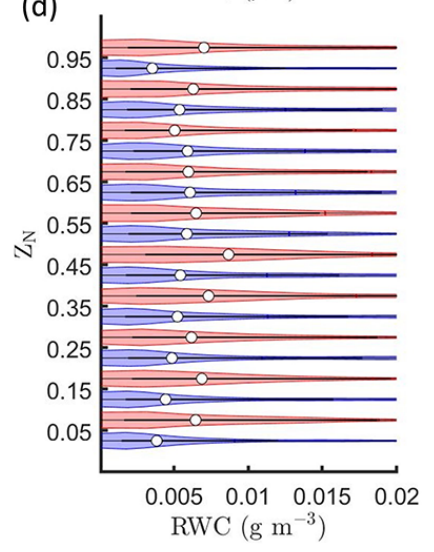

Figure 2. Kernel density estimates (distribution of the data indicated by width of shaded area) and box plots showing the 25th, 50th (white circle), and 75th percentiles for (a) $N_{\mathrm{c}}$, (b) $R_{\mathrm{e}}$, (c) CWC, and (d) RWC as a function of $Z_{\mathrm{N}}$ for contact and separated profiles.

for $D<50 \mu \mathrm{m}$ was defined as CWC. Rainwater path (RWP) and (cloud water path) CWP were defined as the vertical integrals of RWC and CWC, respectively. The median CWC increased with $Z_{\mathrm{N}}$ but decreased over the top $10 \%$ of the cloud layer for contact profiles and over the top $20 \%$ of 
the cloud layer for separated profiles, consistent with cloudtop entrainment (Fig. 2c). For contact profiles, the median RWC increased with $Z_{N}$ before decreasing for $Z_{N} \geq 0.75$. The median RWC for separated profiles varied with $Z_{\mathrm{N}}$. The bottom half of the cloud layer had higher median values (up to $8.7 \times 10^{-3} \mathrm{~g} \mathrm{~m}^{-3}$ ) compared to the top half (up to $7.0 \times 10^{-3} \mathrm{~g} \mathrm{~m}^{-3}$ ) (Fig. 2d).

For contact profiles, there was a significant increase in the average CWC $(10 \%)$ and a significant decrease in the average RWC (60\%) compared to separated profiles (Table 4). Contact profiles also had significantly lower average RWP with insignificant differences for average CWP (Table 4). Contact profiles were located in deeper boundary layers with significantly higher $Z_{\mathrm{B}}$ and $Z_{\mathrm{T}}$ compared to separated profiles. However, the decrease in RWC cannot be attributed to differences in $H$ or LWP (Kubar et al., 2009) because of statistically similar $H$ and LWP for contact and separated profiles, on average (Table 4). These results show that instances of contact between above-cloud aerosols and the MSC were associated with more numerous and smaller cloud droplets and weaker droplet growth compared to instances of separation between the above-cloud aerosols and the MSC.

\section{Precipitation formation and $H$}

The precipitation rate $R_{\mathrm{p}}$ was calculated using the drizzle water content and fall velocity $u(D)$ following Abel and Boutle (2012):

$$
R_{\mathrm{p}}=\pi / 6 \int_{50 \mu m}^{\infty} n(D) D^{3} u(D) \mathrm{d} D
$$

with fall velocity relationships from Rogers and Yau (1989) used in the computation.

Contact profiles had significantly lower $R_{\mathrm{p}}$ compared to separated profiles (95\% CIs: 0.03 to $0.05 \mathrm{~mm} \mathrm{~h}^{-1}$ lower). This suggests contact between the MSC and above-cloud biomass burning aerosols was associated with precipitation suppression. LWP and $H$ impact the sign and magnitude of the precipitation changes in response to changes in aerosol conditions (Kubar et al., 2009; Christensen and Stephens, 2012). Thus, cloud and precipitation properties were evaluated as a function of $H$ to examine the aerosol-induced changes in precipitation formation.

The 95th percentile was used to represent the maximum value of a variable. For example, the 95th percentile of $R_{\mathrm{p}}$ (denoted by $R_{\mathrm{p} 95}$ ) represents the maximum $R_{\mathrm{p}}$ during a cloud profile. Although more numerous contact profiles were drizzling compared to separated profiles, the latter had more numerous profiles with high precipitation intensity. For instance, 114 out of 173 contact and 95 out of 156 separated profiles were drizzling with $R_{\mathrm{p} 95}>0.01 \mathrm{~mm} \mathrm{~h}^{-1}$, out of which 36 contact and 40 separated profiles had $R_{\mathrm{p} 95}>0.1 \mathrm{~mm} \mathrm{~h}^{-1}$, and only 1 contact and 9 separated pro- files had $R_{\mathrm{p} 95}>1 \mathrm{~mm} \mathrm{~h}^{-1}$ (Fig. 3a). This is consistent with radar retrievals of surface $R_{\mathrm{p}}<1 \mathrm{~mm} \mathrm{~h}^{-1}$ for over $93 \%$ of the radar profiles from 2016 and 2017 (Dzambo et al., 2019).

\subsection{Microphysical properties}

On average, separated profiles had greater $R_{\mathrm{p} 95}$ $\left(0.22 \mathrm{~mm} \mathrm{~h}^{-1}\right)$ compared to contact profiles $\left(0.07 \mathrm{~mm} \mathrm{~h}^{-1}\right)$. $R_{\mathrm{p} 95}$ was positively correlated with $H$ as thicker profiles had higher precipitation intensity (Fig. 3a). The average $R_{\mathrm{p} 95}$ increased from thin $(H<175 \mathrm{~m})$ to thick clouds $(H>175 \mathrm{~m})$ from 0.04 to $0.10 \mathrm{~mm} \mathrm{~h}^{-1}$ for contact and 0.13 to $0.29 \mathrm{~mm} \mathrm{~h}^{-1}$ for separated profiles. Precipitation intensity thus decreased from separated to contact profiles for both thin and thick profiles. The average $R_{\mathrm{p} 95}$ for thin and thick contact profiles was $32 \%$ and $37 \%$ of the average $R_{\mathrm{p} 95}$ for thin and thick separated profiles, respectively.

$\mathrm{CWC}_{95}$ was positively correlated with $H$ as thicker clouds had higher droplet mass (Fig. 3b). This was consistent with condensational and collision-coalescence growth continuing to occur with greater height above cloud base (Fig. 2b, c) and greater cloud depth allowing for greater droplet growth. $N_{\mathrm{c} 95}$ and $R_{\mathrm{e} 95}$ were negatively and positively correlated with $H$, respectively (Fig. 3c, d). The trends in $N_{\mathrm{c}}$ and $R_{\mathrm{e}}$ versus $H$ were consistent with the process of collision-coalescence resulting in fewer and larger droplets.

On average, contact profiles had higher $N_{\mathrm{c} 95}$ and lower $R_{\mathrm{e} 95}\left(311 \mathrm{~cm}^{-3}\right.$ and $\left.8.6 \mu \mathrm{m}\right)$ compared to separated profiles $\left(166 \mathrm{~cm}^{-3}\right.$ and $\left.10.8 \mu \mathrm{m}\right)$. It can be inferred that the presence of more numerous and smaller droplets during contact profiles decreased the efficiency of collision-coalescence. Alternatively, there may not have been sufficient time for the updraft to produce the few large droplets needed to broaden the size distribution and initiate collision-coalescence. Since contact and separated profiles had statistically similar $H$ (Table 4), the following discussion examines the link between precipitation suppression and the aerosol-induced changes in $N_{\mathrm{c}}, R_{\mathrm{e}}$, and LWC and their impact on precipitation.

\subsection{Precipitation properties}

Precipitation formation process rates were estimated using equations used in numerical models to compare precipitation formation between contact and separated profiles. Precipitation development in models is parameterized using bulk microphysical schemes. General circulation models (GCMs) or large eddy simulation (LES) models parameterize precipitation formation using $S_{\mathrm{AUTO}}$ and $S_{\mathrm{ACC}}$ (e.g., Penner et al., 2006; Morrison and Gettelman, 2008; Gordon et al., 2018). The most commonly used parameterizations were used to estimate equivalent rates of precipitation formation from models. $S_{\mathrm{AUTO}}$ and $S_{\mathrm{ACC}}$ were calculated following Khairoutdinov and Kogan (2000):

$$
S_{\mathrm{AUTO}}=\left(\mathrm{d} w_{\mathrm{r}}\right)_{\mathrm{AUTO}} / \mathrm{d} t=1350 w_{\mathrm{c}}^{2.47} N_{\mathrm{c}}^{-1.79}
$$


Table 4. Average and standard deviation for cloud properties measured during contact and separated profiles with $95 \%$ confidence intervals (CIs) from a two-sample $t$ test applied to contact and separated profile data. Positive CIs indicate higher average for contact profiles, and "insignificant" indicates statistically similar averages for contact and separated profiles.

\begin{tabular}{lrrl}
\hline Parameter & Contact & Separated & $95 \%$ CIs \\
\hline$N_{\mathrm{c}}\left(\mathrm{cm}^{-3}\right)$ & $200 \pm 103$ & $113 \pm 63$ & 84 to 90 \\
$R_{\mathrm{e}}(\mu \mathrm{m})$ & $7.5 \pm 2.1$ & $9 \pm 3$ & -1.6 to -1.4 \\
$\tau$ & $8.8 \pm 8.3$ & $7 \pm 5$ & 0.04 to 3.06 \\
$\mathrm{LWC}\left(\mathrm{g} \mathrm{m}^{-3}\right)$ & $0.23 \pm 0.17$ & $0.21 \pm 0.14$ & 0.01 to 0.02 \\
$\mathrm{CWC}\left(\mathrm{g} \mathrm{m}^{-3}\right)$ & $0.22 \pm 0.16$ & $0.20 \pm 0.14$ & 0.01 to 0.02 \\
$\mathrm{RWC}\left(\times 10^{-3} \mathrm{~g} \mathrm{~m}^{-3}\right)$ & $11 \pm 15$ & $18 \pm 31$ & -8 to -6 \\
$H(\mathrm{~m})$ & $194 \pm 109$ & $208 \pm 106$ & insignificant \\
$\mathrm{LWP}\left(\mathrm{g} \mathrm{m}^{-2}\right)$ & $46 \pm 49$ & $46 \pm 41$ & insignificant \\
$\mathrm{CWP}\left(\mathrm{g} \mathrm{m}^{-2}\right)$ & $45 \pm 50$ & $46 \pm 44$ & insignificant \\
$\mathrm{RWP}\left(\mathrm{g} \mathrm{m}^{-2}\right)$ & $1.8 \pm 3.3$ & $3.0 \pm 7.1$ & -2.4 to -0.01 \\
$Z_{\mathrm{T}}(\mathrm{m})$ & $1069 \pm 267$ & $1004 \pm 271$ & 6 to 123 \\
$Z_{\mathrm{B}}(\mathrm{m})$ & $874 \pm 294$ & $796 \pm 274$ & 16 to 140 \\
$R_{\mathrm{p}}\left(\mathrm{mm} \mathrm{h}^{-1}\right)$ & $0.04 \pm 0.09$ & $0.08 \pm 0.33$ & -0.05 to -0.03 \\
$S_{\mathrm{AUTO}}\left(\times 10^{-10} \mathrm{~s}^{-1}\right)$ & $1.6 \pm 3.0$ & $4.9 \pm 12.6$ & -3.6 to -3.1 \\
$S_{\mathrm{ACC}}\left(\times 10^{-8} \mathrm{~s}^{-1}\right)$ & $0.8 \pm 1.6$ & $1.7 \pm 4.3$ & -1.1 to -0.8 \\
$S_{\mathrm{ACC}} / S_{\mathrm{AUTO}}\left(\times 10^{2}\right)$ & $0.7 \pm 1.1$ & $0.5 \pm 0.9$ & 0.2 to 0.3 \\
\hline
\end{tabular}
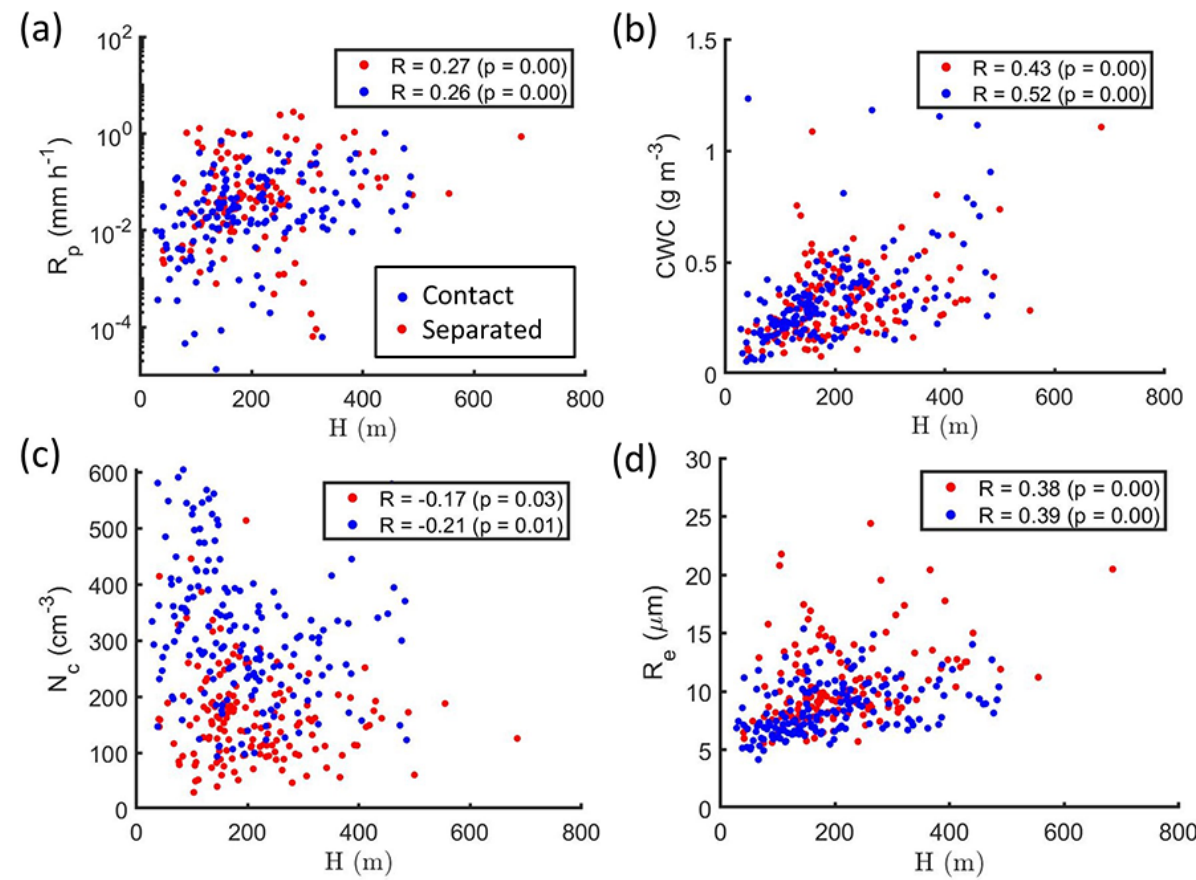

Figure 3. The 95th percentile for (a) $R_{\mathrm{p}}$, (b) CWC, (c) $N_{\mathrm{c}}$, and (d) $R_{\mathrm{e}}$ as a function of $H$. Each dot represents the 95th percentile from the $1 \mathrm{~Hz}$ measurements for a single cloud profile. Pearson's correlation coefficient $(R)$ and $p$ value for the correlation indicated in legend.

and

$S_{\mathrm{ACC}}=\left(\mathrm{d} w_{\mathrm{r}}\right)_{\mathrm{ACC}} / \mathrm{d} t=67\left(w_{\mathrm{c}} w_{\mathrm{r}}\right)^{1.15}$,

where $w_{\mathrm{c}}$ and $w_{\mathrm{r}}$ are cloud water and rainwater mixing ratios, respectively, and are equal to the CWC and RWC divided by the density of air $\left(\rho_{\mathrm{a}}\right)$.
Contact profiles had significantly lower $S_{\mathrm{AUTO}}$ and $S_{\mathrm{ACC}}$ compared to separated profiles (Table 4). This is consistent with significantly lower RWC and $R_{\mathrm{p}}$ for contact profiles and the association of $S_{\mathrm{AUTO}}$ and $S_{\mathrm{ACC}}$ with precipitation onset and precipitation intensity, respectively. $S_{\mathrm{AUTO}} 95$ and $S_{\text {ACC95 }}$ were positively correlated with $H$ (Fig. $4 \mathrm{a}, \mathrm{b}$ ). Separated profiles had higher $S_{\text {AUTO95 }}$ and $S_{\text {ACC95 }}\left(9.6 \times 10^{-10}\right.$ 
and $\left.2.2 \times 10^{-8} \mathrm{~s}^{-1}\right)$ compared to contact profiles $\left(2.9 \times 10^{-10}\right.$ and $\left.1.2 \times 10^{-8} \mathrm{~s}^{-1}\right)$, associated with the inverse relationship between $S_{\mathrm{AUTO}}$ and $N_{\mathrm{c}}$ (Eq. 6). Faster autoconversion resulted in higher drizzle water content and greater accretion of droplets on drizzle drops.

The sampling of lower $N_{\mathrm{c} 95}$ and higher $R_{\mathrm{e} 95}$ compared to thinner profiles suggests that collision-coalescence was more effective in profiles with higher $H$ (Fig. 3c, d). Thin contact profiles had the lowest $S_{\text {AUTO95 }}\left(1.4 \times 10^{-10} \mathrm{~s}^{-1}\right)$, followed by thick contact $\left(4.5 \times 10^{-10} \mathrm{~s}^{-1}\right)$, thin separated $(4.7 \times$ $\left.10^{-10} \mathrm{~s}^{-1}\right)$, and thick separated profiles $\left(1.4 \times 10^{-9} \mathrm{~s}^{-1}\right)$. High $N_{\mathrm{c}}$ and low CWC for thin contact profiles (Fig. 3b, c) are consistent with increased competition for cloud water leading to weaker autoconversion. It is hypothesized that these microphysical differences resulted in the lower $S_{\mathrm{AUTO} 95}$ and $R_{\mathrm{p} 95}$ for thin contact profiles compared to other profiles. The differences between $R_{\mathrm{p}}$ for contact and separated profiles thus varied with $H$ in addition to $N_{\mathrm{c}}, R_{\mathrm{e}}$, and CWC. $N_{\mathrm{c}}, R_{\mathrm{e}}$, and CWC varied with $N_{\mathrm{a}}$ (Sect. 4 ), and ACIs were examined in Sects. 6 and 7.

\section{Aerosol influence on precipitation}

\subsection{Below-cloud $N_{a}$}

Polluted boundary layers in the Southeast Atlantic are associated with entrainment mixing between the free troposphere and the boundary layer (Diamond et al., 2018). Groundbased observations from Ascension Island have shown clean boundary layers can have elevated biomass burning trace gas concentrations during the burning season (Pennypacker et al., 2020). This suggests boundary layers could be clean in terms of $N_{\mathrm{a}}$ despite the entrainment of biomass burning aerosols into the boundary layer due to precipitation scavenging of below-cloud aerosols. Carbon monoxide (CO) concentrations were examined since $\mathrm{CO}$ acts as a biomass burning tracer that is unaffected by precipitation scavenging (Pennypacker et al., 2020). For the 2016 IOP, contact profiles were located in boundary layers with significantly higher $N_{\mathrm{a}}(95 \%$ CIs: 93 to $115 \mathrm{~cm}^{-3}$ higher) and CO (95\% CIs: 13 to $16 \mathrm{ppb}$ higher) compared to separated profiles (G21). This is consistent with data from all three IOPs when contact profiles were located in boundary layers with higher $N_{\mathrm{a}}$ (95\% CIs: 231 to $249 \mathrm{~cm}^{-3}$ higher) and CO (95\% CIs: 27 to 29 ppb higher).

Following G21, 171 contact and 148 separated profiles from the IOPs were classified into four regimes: contact, high $N_{\mathrm{a}}(\mathrm{C}-\mathrm{H})$; contact, low $N_{\mathrm{a}}(\mathrm{C}-\mathrm{L})$; separated, high $N_{\mathrm{a}}(\mathrm{S}-\mathrm{H})$; and separated, low $N_{\mathrm{a}}(\mathrm{S}-\mathrm{L})$, where "low $N_{\mathrm{a}}$ " meant the profile was in a boundary layer with $N_{\mathrm{a}}<350 \mathrm{~cm}^{-3}$ up to $100 \mathrm{~m}$ below cloud base. Boundary layer $\mathrm{CO}$ concentration above $100 \mathrm{ppb}$ was sampled during 107 contact and 31 separated profiles, respectively. Contact profiles were more often located in high $N_{\mathrm{a}}$ boundary layers (131 out of 171 profiles classified as $\mathrm{C}-\mathrm{H}$ ), while separated profiles were more often located in low $N_{\mathrm{a}}$ boundary layers (108 out of 148 profiles classified as S-L). This suggests contact between MSC cloud tops and above-cloud biomass burning aerosols was associated with the entrainment of biomass burning aerosols into the boundary layer.

Contact profiles had significantly higher $N_{\mathrm{c}}$ and significantly lower $R_{\mathrm{e}}$ relative to separated profiles in both high $N_{\mathrm{a}}(\mathrm{C}-\mathrm{H}$ relative to $\mathrm{S}-\mathrm{H})$ and low $N_{\mathrm{a}}(\mathrm{C}-\mathrm{L}$ relative to $\mathrm{S}-\mathrm{L})$ boundary layers (Fig. 5, Table 5). This was associated with significantly higher above- and below-cloud $N_{\mathrm{a}}$ for the contact profiles. The differences in $N_{\mathrm{c}}$ and $R_{\mathrm{e}}$ were higher in high $N_{\mathrm{a}}$ boundary layers, where the differences in above- and below-cloud $N_{\mathrm{a}}$ were also higher compared to low $N_{\mathrm{a}}$ boundary layers (Table 5). This is consistent with previous observations of MSC properties (Diamond et al., 2018; Mardi et al., 2019) and similar analysis for data from the 2016 IOP (G21).

C-L profiles had significantly higher $N_{\mathrm{c}}(95 \%$ CIs: 5 to $14 \mathrm{~cm}^{-3}$ higher) compared to $\mathrm{S}-\mathrm{H}$ profiles, despite having significantly lower below-cloud $N_{\mathrm{a}}\left(95 \%\right.$ CIs: 69 to $85 \mathrm{~cm}^{-3}$ lower). Significantly higher above-cloud $N_{\mathrm{a}}$ for C-L profiles (95\% CIs: 321 to $361 \mathrm{~cm}^{-3}$ higher) suggests that this was associated with the influence of above-cloud $N_{\mathrm{a}}$ on $N_{\mathrm{c}}$. However, the smaller difference in $N_{\mathrm{c}}$ compared to the differences between $\mathrm{C}-\mathrm{H}$ and S-H or C-L and S-L profiles suggests the combined impact of above- and below-cloud $N_{\mathrm{a}}$ was stronger than the impact of above-cloud $N_{\mathrm{a}}$ alone. These comparisons were qualitatively consistent when thresholds of 300 or $400 \mathrm{~cm}^{-3}$ were used to define a low $N_{\mathrm{a}}$ boundary layer.

\section{$6.2 N_{\mathrm{c}}$ and $R_{\mathrm{p}}$ versus $H$}

The cloud profiles were divided into four populations based on $H$ to compare $N_{\mathrm{c}}$ and $R_{\mathrm{p}}$ between different aerosols conditions, while $H$ was constrained. The populations were divided at $H=129,175$, and $256 \mathrm{~m}$ to ensure similar sample sizes (Table 6). For each population, contact profiles had higher $N_{\mathrm{c}}$ and lower $R_{\mathrm{p}}$ (Fig. 6a, b), consistent with comparisons averaged over all profiles (Table 4). Due to collisioncoalescence, the average $N_{\mathrm{c}}$ decreased, and the average $R_{\mathrm{p}}$ increased with $H$ (Fig. 6a, b). For contact profiles, the average $N_{\mathrm{c}}$ decreased with $H$ from 221 to $191 \mathrm{~cm}^{-3}$, and the average $R_{\mathrm{p}}$ increased from 0.03 to $0.07 \mathrm{~mm} \mathrm{~h}^{-1}$. For separated profiles, the average $N_{\mathrm{c}}$ decreased from 149 to $92 \mathrm{~cm}^{-3}$, and the average $R_{\mathrm{p}}$ increased from 0.06 to $0.21 \mathrm{~mm} \mathrm{~h}^{-1}$ over the same range of $H$. C-H profiles had the highest average $N_{\mathrm{c}}$ and the lowest average $R_{\mathrm{p}}$ among the four regimes due to high above- and below-cloud $N_{\mathrm{a}}$ (Fig. 6c, d). C-H profiles had the smallest increase in the average $R_{\mathrm{p}}$ with $H(0.02$ to $0.04 \mathrm{~mm} \mathrm{~h}^{-1}$ ). Conversely, low above- and below-cloud $N_{\mathrm{a}}$ for S-L profiles was associated with the lowest average $N_{\mathrm{c}}$, the highest average $R_{\mathrm{p}}$, and the highest increase in the average $R_{\mathrm{p}}$ with $H\left(0.12\right.$ to $\left.0.29 \mathrm{~mm} \mathrm{~h}^{-1}\right)$. For each regime, the average $N_{\mathrm{c}}$ decreased with $H$ (except C-L), and the average $R_{\mathrm{p}}$ increased with $H$ (Fig. 6c, d). 

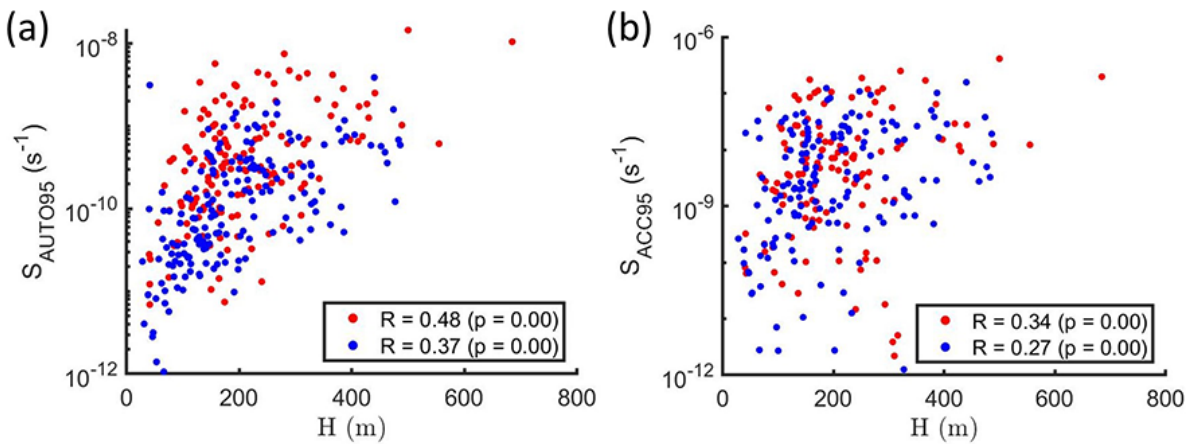

Figure 4. The 95th percentile for (a) $S_{\mathrm{AUTO}}$ and (b) $S_{\mathrm{ACC}}$ as a function of $H$. Each dot represents the 95 th percentile from the $1 \mathrm{~Hz}$ measurements for a single cloud profile. $R$ and $p$ value for the correlation indicated in legend.

Table 5. Average values for aerosol and cloud properties from C-H, S-H, C-L, and S-L regimes (defined in text), along with differences reported as $95 \%$ CIs.

\begin{tabular}{lrrrrrr}
\hline Parameter & C-H & S-H & C-H relative to S-H & C-L & S-L & C-L relative to S-L \\
\hline Above-cloud $N_{\mathrm{a}}\left(\mathrm{cm}^{-3}\right)$ & 1120 & 220 & 852 to 948 & 562 & 161 & 387 to 413 \\
Below-cloud $N_{\mathrm{a}}\left(\mathrm{cm}^{-3}\right)$ & 498 & 288 & 194 to 226 & 211 & 162 & 45 to 53 \\
$N_{\mathrm{c}}\left(\mathrm{cm}^{-3}\right)$ & 226 & 123 & 98 to 108 & 132 & 104 & 25 to 31 \\
$R_{\mathrm{e}}(\mu \mathrm{m})$ & 7.0 & 8.6 & -1.6 to -1.8 & 9.0 & 9.3 & -0.2 to -0.5 \\
$R_{\mathrm{p}}\left(\times 10^{-3} \mathrm{~mm} \mathrm{~h}^{-1}\right)$ & 26 & 64 & -32 to -44 & 83 & 100 & 0.3 to -36 \\
\hline
\end{tabular}

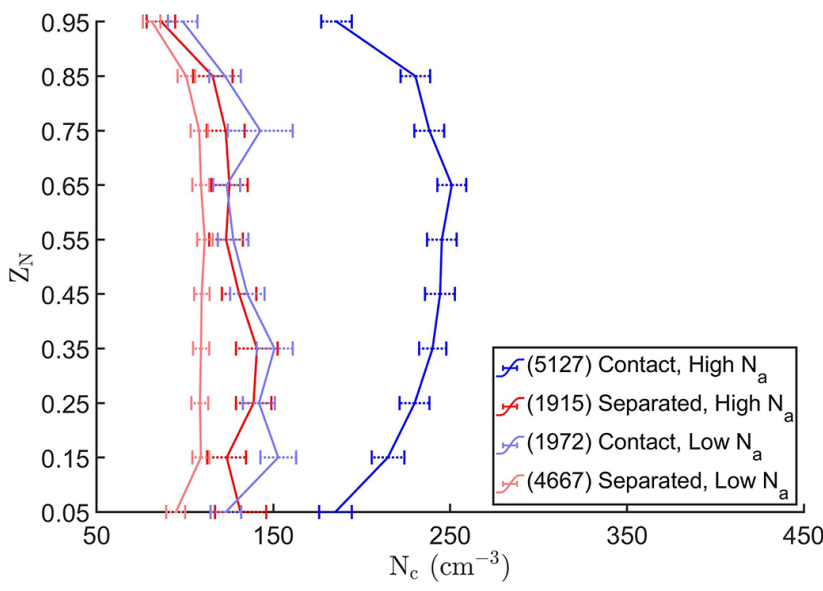

Figure 5. Average $N_{\mathrm{c}}$ (error bars extend to $95 \% \mathrm{CIs}$ ) as a function of $Z_{\mathrm{N}}$. Number of $1 \mathrm{~Hz}$ data points and corresponding regimes indicated in legend.

\subsection{Precipitation susceptibility $S_{0}$}

$S_{\mathrm{o}}$ was used to evaluate the dependence of $R_{\mathrm{p}}$ on $N_{\mathrm{c}}$ under the different aerosol conditions. $S_{\mathrm{o}}$, defined as the negative slope between the natural logarithms of $R_{\mathrm{p}}$ and $N_{\mathrm{c}}$ (Feingold and Seibert, 2009), is given by

$S_{\mathrm{o}}=-\mathrm{d} \ln \left(R_{\mathrm{p}}\right) / \mathrm{d} \ln \left(N_{\mathrm{c}}\right)$,

where a positive value indicates decreasing $R_{\mathrm{p}}$ with increasing $N_{\mathrm{c}}$, in accordance with the "lifetime effect" (Albrecht,
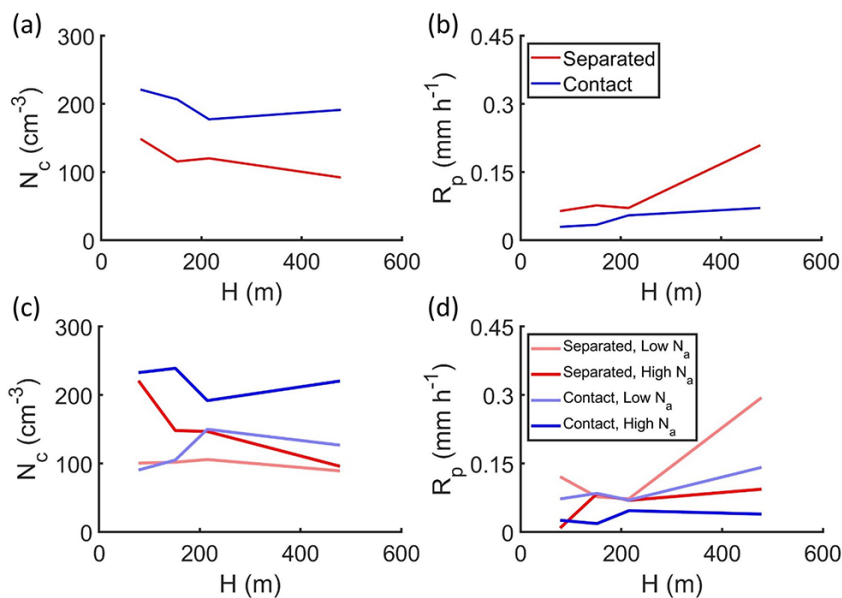

Figure 6. The average (a, c) $N_{\mathrm{c}}$ and $(\mathbf{b}, \mathbf{d}) R_{\mathrm{p}}$ as a function of $H$ for $(\mathbf{a}, \mathbf{b})$ contact and separated profiles and $(\mathbf{c}, \mathbf{d})$ the regimes indicated in legend.

1989). The average $S_{\mathrm{o}}$ across all profiles was $0.88 \pm 0.03$, with lower $S_{0}$ for contact profiles $(0.87 \pm 0.04)$ compared to separated profiles $(1.08 \pm 0.04)$ (Table 6). This is consistent with the hypothesis of lower values for $S_{0}$ analogues (where $N_{\mathrm{c}}$ in Eq. (8) is replaced by $N_{\mathrm{a}}$ ) in the presence of abovecloud aerosols (Duong et al., 2011). $S_{\mathrm{o}}$ depends on the ratio of $S_{\mathrm{ACC}}$ to $S_{\mathrm{AUTO}}$ because $S_{\mathrm{ACC}}$ is independent of $N_{\mathrm{c}}$, and higher $S_{\mathrm{ACC}} / S_{\mathrm{AUTO}}$ represents weaker dependence of $R_{\mathrm{p}}$ on $N_{\mathrm{c}}$ (Wood et al., 2009; Jiang et al., 2010). Lower $S_{\mathrm{o}}$ for con- 
Table 6. $S_{\mathrm{O}} \pm$ standard error for contact, separated, and all profiles, with sample size and $R$ in parentheses. The use of italics denotes the statistical insignificance of $S_{0}$.

\begin{tabular}{lrrr}
\hline$H$ & Contact & Separated & All profiles \\
\hline All & $0.87 \pm 0.04(173,0.30)$ & $1.08 \pm 0.04(156,0.36)$ & $0.88 \pm 0.03(329,0.33)$ \\
28 to $129 \mathrm{~m}$ & $-0.06 \pm 0.11(52,-0.03)$ & $1.47 \pm 0.10(30,0.55)$ & $0.67 \pm 0.07(82,0.28)$ \\
129 to $175 \mathrm{~m}$ & $0.88 \pm 0.06(38,0.42)$ & $0.53 \pm 0.09(42,0.20)$ & $0.68 \pm 0.05(80,0.32)$ \\
175 to $256 \mathrm{~m}$ & $0.92 \pm 0.08(41,0.27)$ & $0.34 \pm 0.07(44,0.13)$ & $0.54 \pm 0.05(85,0.20)$ \\
256 to $700 \mathrm{~m}$ & $1.15 \pm 0.06(42,0.36)$ & $1.45 \pm 0.07(40,0.41)$ & $1.13 \pm 0.04(82,0.40)$ \\
\hline
\end{tabular}
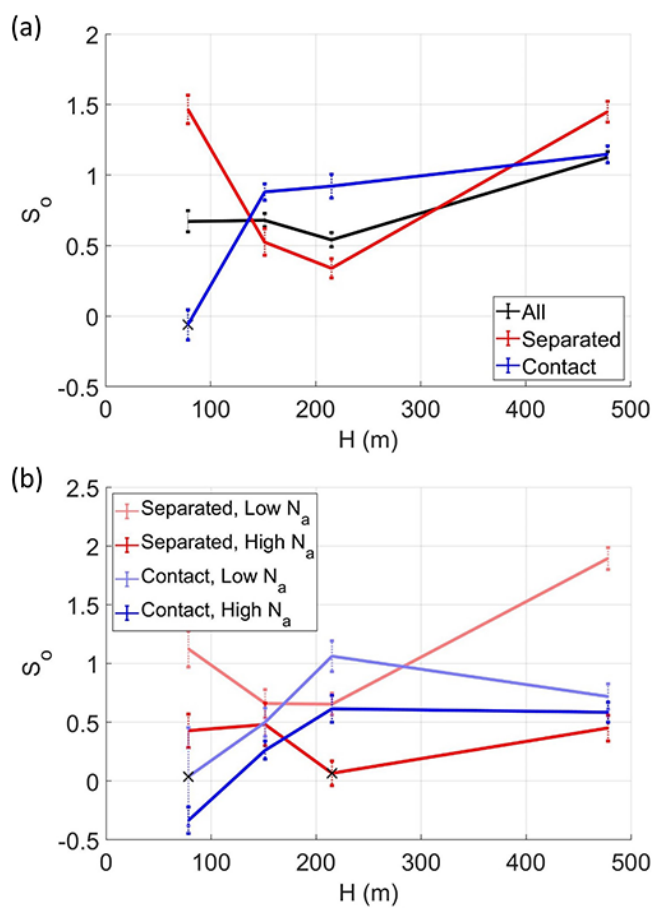

Figure 7. $S_{\mathrm{O}}$ as a function of $H$ (error bars extend to standard error from the regression model) for (a) contact, separated, and all profiles and (b) the regimes indicated in legend. $S_{\mathrm{O}}$ was statistically insignificant when marked with a cross.

tact profiles was associated with higher $S_{\mathrm{ACC}} / S_{\mathrm{AUTO}}$ compared to separated profiles (Table 4).

$S_{\mathrm{o}}$ was calculated as a function of $H$ using $N_{\mathrm{c}}$ and $R_{\mathrm{p}}$ for the four populations of cloud profiles (Fig. 7). The sensitivity of $S_{\mathrm{o}}$ to the number of populations is discussed in Appendix A. Averaged over all profiles, $S_{\mathrm{o}}$ had minor variations with $H$ (e.g., $0.67,0.68$, and 0.54 as $H$ increased) before increasing to 1.13 for $H>256 \mathrm{~m}$ (Table 6). This trend in $S_{0}$ versus $H$ is consistent with previous analyses of $S_{\mathrm{o}}$ (Sorooshian et al., 2009; Jung et al., 2016). However, different trends emerged when $S_{\mathrm{o}}$ was calculated for contact and separated profiles.

The largest difference between $S_{\mathrm{o}}$ for contact and separated profiles was observed for thin clouds with $H<129 \mathrm{~m}$. The 30 separated profiles with $H<129 \mathrm{~m}$ had the highest $S_{\mathrm{o}}$ $(1.47 \pm 0.10)$ because of strong dependence of $R_{\mathrm{p}}$ on $N_{\mathrm{c}}$. For
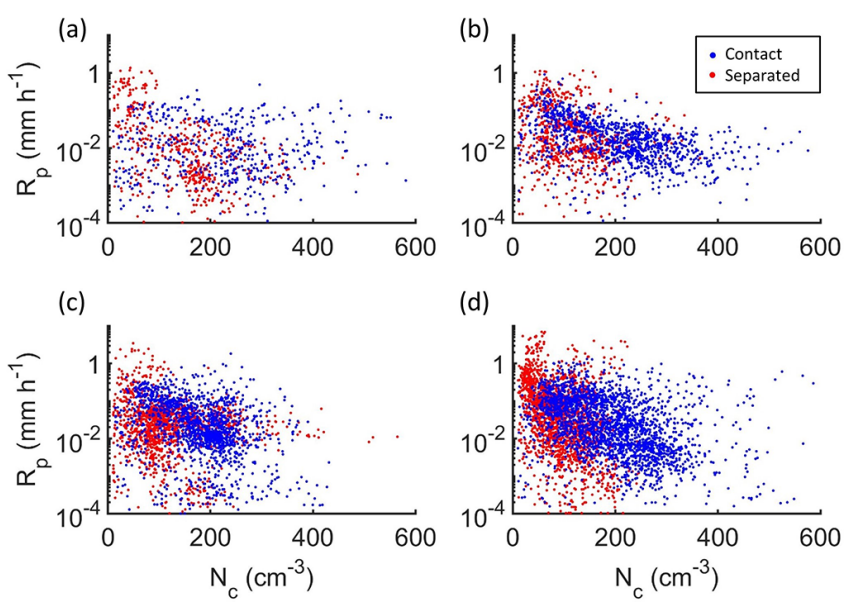

Figure 8. Scatter plots of $R_{\mathrm{p}}$ and $N_{\mathrm{c}}$ for $1 \mathrm{~Hz}$ data points from contact and separated profiles with (a) $28<H<129 \mathrm{~m}$, (b) $129<H<175 \mathrm{~m}$, (c) $175<H<256 \mathrm{~m}$, and (d) $256<H<700 \mathrm{~m}$.

these profiles, measurements with low $N_{\mathrm{c}}\left(<100 \mathrm{~cm}^{-3}\right)$ had higher $R_{\mathrm{p}}\left(0.18 \mathrm{~mm} \mathrm{~h}^{-1}\right)$ compared to measurements with higher $N_{\mathrm{c}}\left(0.01 \mathrm{~mm} \mathrm{~h}^{-1}\right)$ (Fig. $\left.8 \mathrm{a}\right)$. In contrast, the 52 contact profiles with $H<129 \mathrm{~m}$ had a low and statistically insignificant value for $S_{\mathrm{o}}(-0.06 \pm 0.11)$ due to poor (and statistically insignificant) correlation $(R=-0.03)$. Poor correlation between $N_{\mathrm{c}}$ and $R_{\mathrm{p}}$ for contact profiles was associated with precipitation suppression and weaker droplet growth (Sect. 5). These factors resulted in $R_{\mathrm{p}}<0.03 \mathrm{~mm} \mathrm{~h}^{-1}$ independent of the $N_{\mathrm{c}}$ measurement (Fig. 8a).

For separated profiles, $S_{\mathrm{o}}$ decreased with $H$ from $1.47 \pm$ 0.10 for $H<129 \mathrm{~m}$ to $0.53 \pm 0.09$ for $129<H<175 \mathrm{~m}$ and to $0.34 \pm 0.07$ for $175<H<256 \mathrm{~m}$ (Fig. 7a). This was due to the increase in average $R_{\mathrm{p}}$ for high $N_{\mathrm{c}}$ measurements as a function of $H$ from $0.01 \mathrm{~mm} \mathrm{~h}^{-1}$ to 0.05 and $0.04 \mathrm{~mm} \mathrm{~h}^{-1}$, respectively. $R_{\mathrm{p}}$ increased with $H$ due to stronger collisioncoalescence as droplet mass increased with $H$. Separated profiles with $H>256 \mathrm{~m}$ had lower $N_{\mathrm{c}}$ and higher $R_{\mathrm{p}}$ compared to the populations with lower $H$ (Fig. 6a, b). For measurements with low $N_{\mathrm{c}}$, collision-coalescence and stronger autoconversion (following Eq. 6) resulted in higher $R_{\mathrm{p}}$ $\left(0.26 \mathrm{~mm} \mathrm{~h}^{-1}\right)$ compared to measurements with higher $N_{\mathrm{c}}$ $\left(0.13 \mathrm{~mm} \mathrm{~h}^{-1}\right)$. This led to a strong gradient $R_{\mathrm{p}}$ as a function 
of $N_{\mathrm{c}}$ (Fig. $8 \mathrm{~d}$ ), and $S_{\mathrm{o}}$ increased to $1.45 \pm 0.07$ for separated profiles with $H>256 \mathrm{~m}$.

For contact profiles with $H>129 \mathrm{~m}$, the average $R_{\mathrm{p}}$ increased with $H$, with a larger increase for measurements with low $N_{\mathrm{c}}\left(0.028\right.$ to $\left.0.12 \mathrm{~mm} \mathrm{~h}^{-1}\right)$ compared to measurements with high $N_{\mathrm{c}}\left(0.03\right.$ to $\left.0.06 \mathrm{~mm} \mathrm{~h}^{-1}\right)$. It is hypothesized that collision-coalescence was hindered by the presence of more numerous droplets for the latter. With droplet growth and collision-coalescence for higher $H$, the limiting factor for $R_{\mathrm{p}}$ changed from $H$ to $N_{\mathrm{c}}$. The dependence of $R_{\mathrm{p}}$ on $N_{\mathrm{c}}$ thus increased with $H$, and, as a result, $S_{\mathrm{o}}$ increased with $H$ from $0.88 \pm 0.06$ to $1.15 \pm 0.06$ (Fig. $7 \mathrm{a}$ ).

Among the four regimes defined based on the above- and below-cloud $N_{\mathrm{a}}$, S-L profiles had the highest $S_{\mathrm{o}}$ (1.12) (Table 7). This was associated with S-L profiles having the lowest $N_{\mathrm{c}}$ and the highest $R_{\mathrm{p}}$ among the regimes (Fig. 6c, d). In descending order of $S_{\mathrm{o}}$, S-L profiles were followed by C-L (0.86), S-H (0.50), and C-H profiles (0.33). Profiles in low $N_{\mathrm{a}}$ boundary layers (S-L and C-L) had higher $S_{\mathrm{o}}$ compared to profiles in high $N_{\mathrm{a}}$ boundary layers $(\mathrm{S}-\mathrm{H}$ and $\mathrm{C}-\mathrm{H})$, consistent with wet scavenging of below-cloud aerosols (Duong et al., 2011; Jung et al., 2016).

$\mathrm{C}-\mathrm{L}$ and C-H profiles had similar trends in $S_{\mathrm{O}}$ except for profiles with $H<129 \mathrm{~m}$ (Fig. 7b). C-L profiles had an insignificant value for $S_{\mathrm{o}}$ due to low sample size (4), and C-H profiles had negative $S_{0}$. These were thin profiles with little cloud water (Fig. 4b), high $N_{\mathrm{c}}$ (Fig. 6c), and low $R_{\mathrm{p}}$ (Fig. 6d). It is hypothesized that increasing $N_{\mathrm{c}}$ would provide the cloud water required for precipitation initiation and aid collisioncoalescence. A total of 107 out of 148 separated profiles were classified as S-L profiles. As a result, separated and S-L profiles had similar trends in $S_{\mathrm{o}}$ versus $H$ (Fig. 7). On average, S-L profiles had higher $S_{\mathrm{o}}$ than S-H profiles, which could be associated with wet scavenging, resulting in the lower belowcloud $N_{\mathrm{a}}$ for S-L profiles. For S-H profiles, $S_{\mathrm{o}}$ was constant with $H$ at about 0.45 (except $175<H<256 \mathrm{~m}$ when the value for $S_{0}$ was insignificant).

The sensitivity of $S_{\mathrm{o}}$ to removal of clouds based on $R_{\mathrm{p}}$ was examined in Appendix B. The removal of clouds with low $R_{\mathrm{p}}$ and high $N_{\mathrm{c}}$ or with high $R_{\mathrm{p}}$ and low $N_{\mathrm{c}}$ resulted in lower average $S_{0}$ consistent with previous work (Duong et al., 2011). The $S_{\mathrm{o}}$ comparisons between profiles located in high $N_{\mathrm{a}}$ or low $N_{\mathrm{a}}$ boundary layers varied with the sample sizes of the populations. The sample sizes varied based on the threshold used to define a low $N_{\mathrm{a}}$ boundary layer which is discussed in Appendix C. CAS data were used to represent measurements of droplets with $D<50 \mu \mathrm{m}$ collected during ORACLES 2016 in the absence of CDP data. The sensitivity of $S_{\mathrm{o}}$ to the use of CAS data was examined in Appendix D.

\section{$6.4 S_{0}$ discussion}

Figure 9 shows how $S_{\mathrm{o}}$ varied with perturbations $(\Delta)$ in $N_{\mathrm{c}}$ or $R_{\mathrm{p}}$. Previous studies hypothesized that increasing abovecloud $N_{\mathrm{a}}$ or precipitation scavenging of below-cloud $N_{\mathrm{a}}$

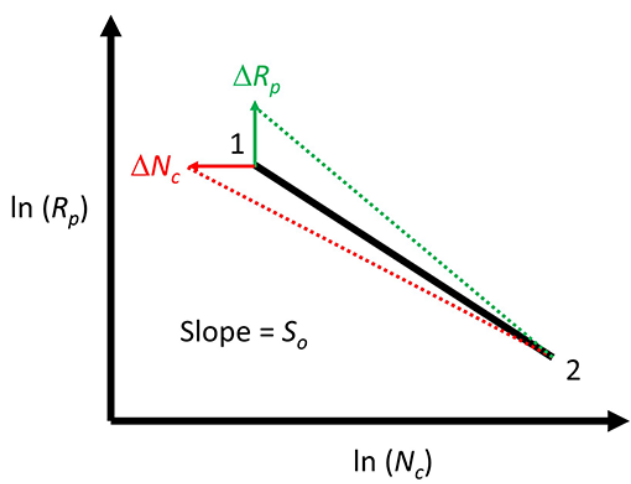

Figure 9. An illustration of the dependence of $S_{\mathrm{O}}$ on $N_{\mathrm{c}}, R_{\mathrm{p}}$, and perturbations $(\Delta)$ in $N_{\mathrm{c}}$ or $R_{\mathrm{p}}$.

would lead to changes in $S_{\mathrm{o}}$ (Fig. 4, Duong et al., 2011; Fig. 11, Jung et al., 2016). Thus, $\Delta N_{\mathrm{c}}$ and $\Delta R_{\mathrm{p}}$ for clouds with variable above- and below-cloud $N_{\mathrm{a}}$ were quantified in this study (Table 5). Higher $N_{\mathrm{c}}$ and lower $R_{\mathrm{e}}$ for contact profiles led to precipitation suppression along with lower $S_{\mathrm{AUTO}}, S_{\mathrm{ACC}}$, and $R_{\mathrm{p}}$, which were associated with lower $S_{\mathrm{o}}$ compared to separated profiles. As a result, polluted clouds were $20 \%$ less susceptible to precipitation suppression than cleaner clouds. Figure 9 shows that the impact of $\Delta N_{\mathrm{c}}$ or $\Delta R_{\mathrm{p}}$ on $S_{\mathrm{o}}$ depends on the original values for $N_{\mathrm{c}}$ and $R_{\mathrm{p}}$ as the same $\Delta N_{\mathrm{c}}$ and $\Delta R_{\mathrm{p}}$ can have an opposing effect on $S_{\mathrm{o}}$. For example, a decrease in $N_{\mathrm{c}}$ at point 1 would decrease the slope and the $S_{\mathrm{o}}$ value, while the same decrease in $N_{\mathrm{c}}$ at point 2 would increase the slope and the $S_{\mathrm{o}}$ value.

Both average and maximum $N_{\mathrm{c}}$ and $R_{\mathrm{p}}$ varied with $H$ due to increasing aerosols (Sect. 4) and droplet growth due to collision-coalescence, autoconversion, and accretion (Sect. 5). Further, co-variability between droplet growth processes and ACIs meant aerosol-induced $\Delta N_{\mathrm{c}}$ and $\Delta R_{\mathrm{p}}$ varied with $H$ (Sect. 6.2). Consequently, the differences between $S_{\mathrm{o}}$ for clean and polluted clouds varied with $H$. The change in $S_{\mathrm{o}}$ was highest for thin polluted clouds due to poor correlation between $N_{\mathrm{c}}$ and $R_{\mathrm{p}}$ as limited droplet growth led to low $R_{\mathrm{p}}$ regardless of the $N_{\mathrm{c}}$. Future work must examine the co-variability between $\Delta N_{\mathrm{c}}$ or $\Delta R_{\mathrm{p}}$ from cloud processes such as droplet growth, entrainment, invigoration, precipitation, and $\Delta N_{\mathrm{c}}$ or $\Delta R_{\mathrm{p}}$ due to ACIs. Model parameterizations with power-law relationships between $R_{\mathrm{p}}, N_{\mathrm{c}}$, and $H$ (Geoffroy et al., 2008) must account for changes in the dependence of $R_{\mathrm{p}}$ on $N_{\mathrm{c}} / H$ due to increasing aerosols or $H$.

The trends in $S_{\mathrm{o}}$ were only compared with studies analyzing airborne data due to the variability in $S_{\mathrm{o}}$ depending on whether aircraft, remote sensing, or modeling data were examined (Sorooshian et al., 2019). Consistent with Terai et al. (2012), $S_{\mathrm{o}}$ decreased with $H$ for separated profiles with $H<256 \mathrm{~m}$. The results from Sect. 5 suggest droplet growth with $H$ decreased the susceptibility to aerosols because $R_{\mathrm{p}}$ was limited by droplet growth instead of $N_{\mathrm{a}}$ or $N_{\mathrm{c}}$. In com- 
Table 7. $S_{\mathrm{O}} \pm$ standard error with sample size and $R$ in parentheses for cloud regimes defined in text. The use of italics denotes the statistical insignificance of $S_{\mathrm{O}}$.

\begin{tabular}{lrrrr}
\hline$H$ & S-L & S-H & C-L & C-H \\
\hline All & $1.29 \pm 0.06(107,0.40)$ & $0.50 \pm 0.06(41,0.19)$ & $0.86 \pm 0.07(40,0.30)$ & $0.33 \pm 0.05(131,0.11)$ \\
28 to $129 \mathrm{~m}$ & $1.12 \pm 0.15(21,0.42)$ & $0.43 \pm 0.14(8,0.27)$ & $0.04 \pm 0.42(4,0.01)$ & $-0.33 \pm 0.11(48,-0.14)$ \\
129 to $175 \mathrm{~m}$ & $0.66 \pm 0.12(25,0.25)$ & $0.48 \pm 0.18(11,0.17)$ & $0.50 \pm 0.12(9,0.25)$ & $0.26 \pm 0.08(27,0.13)$ \\
175 to $256 \mathrm{~m}$ & $0.66 \pm 0.09(34,0.22)$ & $0.07 \pm 0.10(9,0.03)$ & $1.06 \pm 0.13(14,0.34)$ & $0.61 \pm 0.11(27,0.17)$ \\
256 to $700 \mathrm{~m}$ & $1.89 \pm 0.09(27,0.52)$ & $0.45 \pm 0.11(13,0.14)$ & $0.72 \pm 0.11(13,0.24)$ & $0.59 \pm 0.09(29,0.17)$ \\
\hline
\end{tabular}

parison, $S_{\mathrm{o}}$ increased with $H$ for contact profiles, consistent with Jung et al. (2016). The low $S_{\mathrm{o}}$ for thin contact profiles was consistent with the low $S_{\mathrm{o}}(0.06)$ for thin MSC over the southeast Pacific (Jung et al., 2016). This was attributed to insufficient cloud water for precipitation initiation (as noted in Sect. 5). An airborne investigation of marine stratocumulus off the Californian coast attributed negative values of $S_{\mathrm{o}}$ to the influence of giant cloud condensation nuclei (Dadashazar et al., 2017). The authors hypothesized that the low statistical significance of the negative estimate of $S_{0}$ could be associated with precipitation suppression by aerosol particles.

Jung et al. (2016) analyzed MSC sampled farther east and away from South America compared to Terai et al. (2012). They argued a westward increase in precipitation frequency and intensity, along with a decrease in aerosols and $N_{\mathrm{c}}$, led to the differences between the two studies. This same attribution of the role of aerosols can be made for the ORACLES data as there were differences between contact and separated profiles because the MSCs sampled during these profiles were located in similar geographical locations with different aerosol conditions. Modeling studies (e.g., Wood et al., 2009; Gettelman et al., 2013) have shown that $S_{\mathrm{o}}$ increases with $H$ when $S_{\text {AUTO }}$ dominates $S_{\text {ACC }}$ (typically for $R_{\mathrm{e}}<14 \mu \mathrm{m}$, the critical radius for precipitation initiation). Maximum $R_{\mathrm{e}}<14 \mu \mathrm{m}$ was sampled during all but 23 separated and 3 contact profiles (Fig. 4d). This would explain the increase in $S_{\mathrm{o}}$ with $H$ for both contact (for $H>129 \mathrm{~m}$ ) and separated profiles (for $H>256 \mathrm{~m}$ ).

\section{Meteorological influence on LWP}

The relationships between LWP or $H$ and $N_{\mathrm{c}}, R_{\mathrm{e}}$, and LWC depend on meteorological conditions in addition to aerosol properties. The MSC LWP and cloud cover can vary with LTS (Klein and Hartmann, 1993; Mauger and Norris, 2007), estimated inversion strength (EIS) (Wood and Bretherton, 2006), and SST (Wilcox, 2010; Sakaeda et al., 2011). The correlations between LWP / $H$ and these parameters are examined using the European Centre for MediumRange Weather Forecasts (ECMWF) atmospheric reanalysis (ERA5) (Hersbach et al., 2020) to define the meteorological conditions.
ERA5 provides hourly output with a horizontal resolution of $0.25^{\circ} \times 0.25^{\circ}$ for 37 pressure $(p)$ levels (up to $1 \mathrm{hPa}$ ). The cloud sampling for most flights was conducted within $3 \mathrm{~h}$ of 12:00 UTC (Table 2). ERA5 data at 12:00 UTC were thus used for the grid box nearest to the profile (Dzambo et al., 2019). The low cloud cover (LCC), SST, $H_{\mathrm{BL}}$, total column liquid water (ERA5 LWP) and rainwater (ERA5 RWP), mean sea level pressure $\left(p_{0}\right), 2 \mathrm{~m}$ temperature $\left(T_{\mathrm{o}}\right)$, and $2 \mathrm{~m}$ dew point temperature $\left(T_{\mathrm{d}}\right)$ were examined (Table 8$)$.

The difference between potential temperatures at $700 \mathrm{hPa}$ and the surface was defined as LTS (Klein and Hartmann, 1993). EIS was calculated following Wood and Bretherton (2006):

$\mathrm{EIS}=\mathrm{LTS}-\Gamma_{\mathrm{m}}^{850}\left(z_{700}-\mathrm{LCL}\right), \mathrm{LCL}=125\left(T_{\mathrm{o}}-T_{\mathrm{d}}\right)$,

where $\Gamma_{\mathrm{m}}$ is the moist adiabatic potential temperature gradient, $z 700$ is the height at $700 \mathrm{mb}$, and LCL is the lifting condensation level (Lawrence, 2005). $\Gamma_{\mathrm{m}}^{850}$ is $\Gamma_{\mathrm{m}}$ for $850 \mathrm{hPa}$ and calculated following Wood and Bretherton (2006).

LCC refers to cloud fraction for $p>0.8 p_{0}$, corresponding to $p>810 \mathrm{hPa}$, where most profiles were sampled (Table 2). The ECMWF model used a threshold of EIS $>7 \mathrm{~K}$ to distinguish between well-mixed boundary layers topped by stratocumulus and decoupled boundary layers with cumulus clouds (ECMWF, 2020). This distinction improved the agreement between the model LCC and LWP and observations (Köhler et al., 2011). LCC was proportional to EIS / LTS, and LCC $<0.8$ was mostly observed for EIS $<7 \mathrm{~K}$ (Fig. 10a). Decoupled boundary layers can be topped by MSC (G21; Wood, 2012). Profiles with EIS $<7 \mathrm{~K}$ were included in the analysis if ERA5 had LCC $>0.95$. This included 64 contact and 88 separated profiles from the three IOPs. For the 2016, 2017, and 2018 IOPs, 50, 20, and 76 profiles, respectively, had LCC $>0.95$ out of which 0,4 , and 44 profiles, respectively, had EIS $<7 \mathrm{~K}$. The average ERA5 $H_{\mathrm{BL}}$ $(599 \pm 144 \mathrm{~m})$ was lower than the average $Z_{\mathrm{T}}(932 \pm 196 \mathrm{~m})$. This underestimation of $H_{\mathrm{BL}}$ by ERA5 has been observed for stratocumulus over the southeast and northeast Pacific (Ahlgrimm et al., 2009; Hannay et al., 2009).

On average, the ERA5 LWP $\left(51 \pm 21 \mathrm{~g} \mathrm{~m}^{-2}\right)$ was slightly greater than LWP $\left(46 \pm 41 \mathrm{~g} \mathrm{~m}^{-2}\right)$, but the differences were statistically insignificant. There was a significant but weak correlation between LWP and ERA5 LWP $(R=0.18)$ 
Table 8. Meteorological and cloud properties from ERA5 reanalysis for contact, separated, and all profiles with LCC $>0.95$ (LCC is reported for all profiles), $95 \%$ CIs from a two-sample $t$ test applied to contact and separated profile data, and $R$ between each parameter and LWP $\left(R_{\mathrm{LWP}}\right)$ or $H\left(R_{\mathrm{H}}\right)$ with statistically significant $R_{\mathrm{H}}$ and $R_{\mathrm{LWP}}$ in bold.

\begin{tabular}{lrrrlr}
\hline Parameter & Contact & Separated & All & $95 \%$ CIs & $R_{\mathrm{H}}, R_{\mathrm{LWP}}$ \\
\hline LCC & $0.75 \pm 0.29$ & $0.83 \pm 0.26$ & $0.79 \pm 0.28$ & -0.14 to -0.02 & $\mathbf{0 . 2 4}, 0.04$ \\
SST (K) & $293 \pm 2$ & $294 \pm 3$ & $293 \pm 2$ & -1.5 to -0 & $\mathbf{0 . 1 6}, \mathbf{0 . 2 2}$ \\
$H_{\mathrm{BL}}(\mathrm{m})$ & $566 \pm 164$ & $624 \pm 124$ & $600 \pm 144$ & -103 to -11 & $-0.05,-0.11$ \\
ERA5 LWP $\left(\mathrm{g} \mathrm{m}^{-2}\right)$ & $53 \pm 18$ & $51 \pm 23$ & $52 \pm 21$ & insignificant & $\mathbf{0 . 3 1 , 0 . 1 8}$ \\
ERA5 RWP $\left(\mathrm{g} \mathrm{m}^{-2}\right)$ & $0.71 \pm 1.56$ & $0.32 \pm 0.40$ & $0.48 \pm 1.07$ & 0.05 to 0.73 & $\mathbf{0 . 1 9},-0.01$ \\
$P_{\mathrm{O}}(\mathrm{mb})$ & $1015 \pm 1$ & $1014 \pm 2$ & $1014 \pm 2$ & 1 to 2 & $-0.09,-0.07$ \\
$T_{\mathrm{o}}(\mathrm{K})$ & $293 \pm 2$ & $293 \pm 3$ & $293 \pm 2$ & insignificant & $\mathbf{0 . 1 6}, \mathbf{0 . 2 7}$ \\
LTS (K) & $23 \pm 2$ & $22 \pm 3$ & $23 \pm 3$ & insignificant & $-0.10,-\mathbf{0 . 2 9}$ \\
EIS (K) & $8.1 \pm 1.9$ & $7.8 \pm 3.1$ & $7.9 \pm 2.7$ & insignificant & $-0.13,-\mathbf{0 . 3 1}$ \\
\hline
\end{tabular}
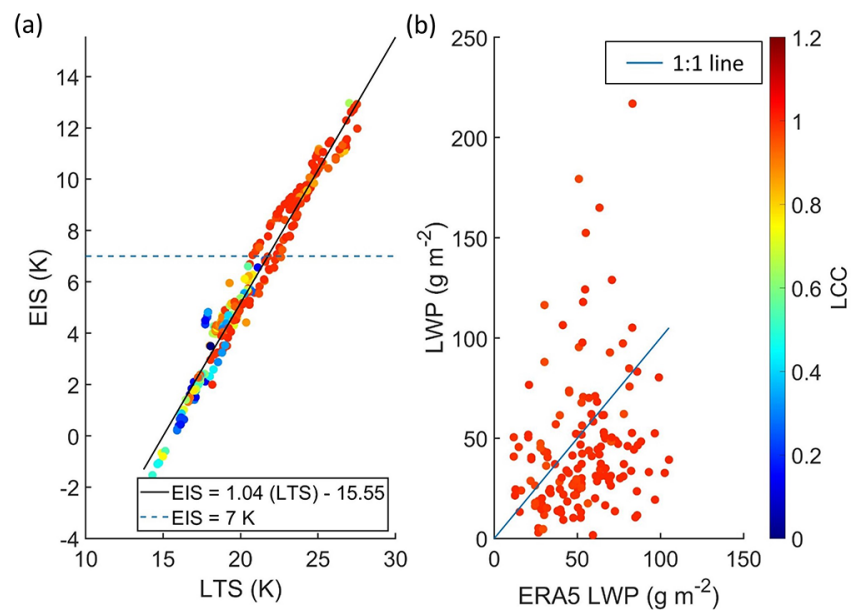

Figure 10. (a) LTS versus EIS with regression coefficients in legend ( $R=0.98)$ and (b) LWP from size-resolved probes versus LWP from the ERA5 reanalysis $(R=0.18)$ where each dot represents a single cloud profile. LTS, EIS, ERA5 LWP, and LCC for each cloud profile taken from the nearest ERA5 grid box (within $0.25^{\circ}$ of latitude and longitude) at 12:00 UTC. Panel (a) shows all cloud profiles and panel (b) shows cloud profiles with LCC $>0.95$.

(Fig. 10b). On average, the ERA5 RWP $\left(0.48 \pm 1.07 \mathrm{~g} \mathrm{~m}^{-2}\right)$ was lower than RWP $\left(1.19 \pm 2.76 \mathrm{~g} \mathrm{~m}^{-2}\right)$. There were insignificant differences between ERA5 LWP and LWP for contact and separated profiles with LCC $>0.95$ (Table 8). Contact profiles with LCC $>0.95$ had significantly higher ERA5 RWP (Table 8). While this is counterintuitive, given the precipitation suppression, it was due to the selection of profiles with $\mathrm{LCC}>0.95$. Contact profiles with $\mathrm{LCC}>0.95$ also had higher in situ RWP (95\% CIs: 0.32 to $2.08 \mathrm{~g} \mathrm{~m}^{-2}$ higher) compared to separated profiles with LCC $>0.95$.

LWP was positively correlated with SST and $T_{\mathrm{O}}$ and negatively correlated with LTS and EIS with weak but statistically significant correlations (Fig. 11). On average, separated profiles had significantly higher SST (95\% CIs: 0.01 to $1.48 \mathrm{~K}$ higher) compared to contact profiles with insignificant dif- ferences between the average $T_{0}$, EIS, and LTS. Since the correlation between LWP / $H$ and SST was weak, it is unlikely the differences between contact and separated profiles were driven by SST differences alone. When all profiles (irrespective of LCC) were considered, there were insignificant differences between the average ERA5 RWP, SST, $T_{0}$, EIS, and LTS for contact and separated profiles. This suggests the differences between contact and separated profiles found during the ORACLES IOPs were primarily associated with ACIs instead of meteorological effects.

\section{Conclusions}

In situ measurements of stratocumulus over the Southeast Atlantic Ocean were collected during the NASA ORACLES field campaign. The microphysical $\left(N_{\mathrm{c}}\right.$ and $\left.R_{\mathrm{e}}\right)$, macrophysical (LWP and $H$ ), and precipitation properties $\left(R_{\mathrm{p}}\right.$ and $\left.S_{\mathrm{o}}\right)$ of the stratocumulus were analyzed. A total of 173 contact profiles with $N_{\mathrm{a}}>500 \mathrm{~cm}^{-3}$ within $100 \mathrm{~m}$ above cloud tops were compared with 156 separated profiles with $N_{\mathrm{a}}<500 \mathrm{~cm}^{-3}$ up to at least $100 \mathrm{~m}$ above cloud tops. Contact between abovecloud aerosols and the stratocumulus was associated with the following:

1. More numerous and smaller droplets with weaker droplet growth with height.

Contact profiles had significantly higher $N_{\mathrm{c}}$ (84 to $90 \mathrm{~cm}^{-3}$ higher) and lower $R_{\mathrm{e}}$ (1.4 to $1.6 \mu \mathrm{m}$ lower $)$ compared to separated profiles. The median $R_{\mathrm{e}}$ had a smaller increase from cloud base to cloud top for contact $(6.1$ to $7.9 \mu \mathrm{m})$ compared to separated profiles (7.1 to $9.5 \mu \mathrm{m})$. The profiles had similar LWP and $H$, and it is hypothesized the differences in droplet growth were associated with collision-coalescence.

2. Aerosol-induced cloud microphysical changes in both clean and polluted boundary layers.

Contact profiles had 25 to $31 \mathrm{~cm}^{-3}$ higher $N_{\mathrm{c}}$ and 0.2 to $0.5 \mu \mathrm{m}$ lower $R_{\mathrm{e}}$ in clean and 98 to $108 \mathrm{~cm}^{-3}$ higher 
(a)

(c)
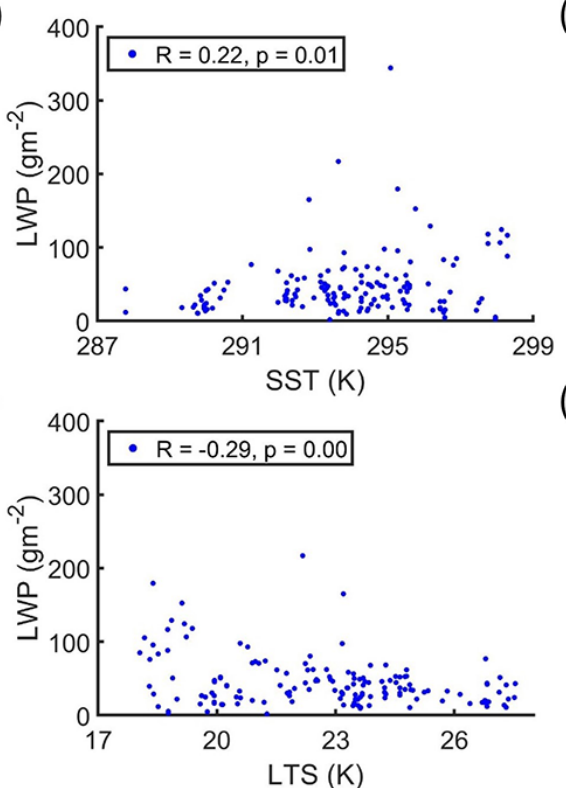

(b)

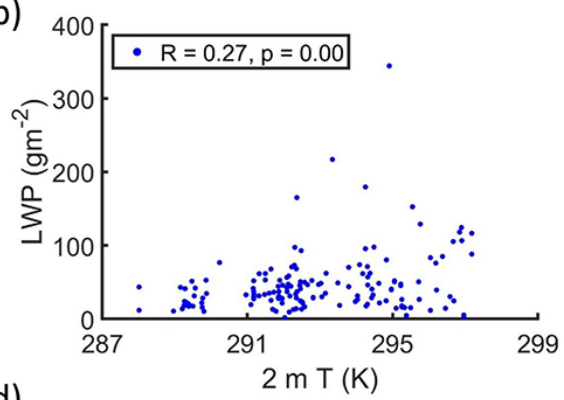

d)

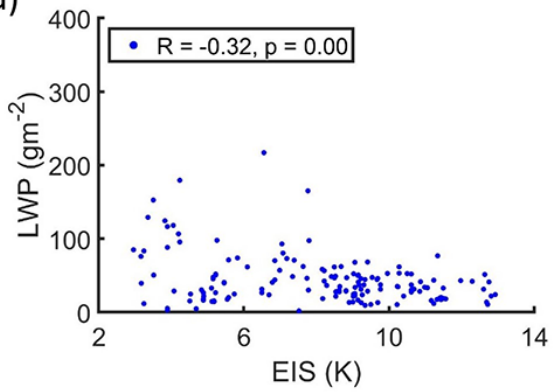

Figure 11. LWP from size-resolved probes as a function of (a) SST, (b) $2 \mathrm{~m} \mathrm{~T}$, (c) LTS, and (d) EIS. Each dot represents a single cloud profile with LCC $>0.95$ and SST, $2 \mathrm{~m} T$, LTS, and EIS taken from the nearest ERA5 grid box (within $0.25^{\circ}$ of latitude and longitude) at 12:00 UTC.

$N_{\mathrm{c}}$ and 1.6 to $1.8 \mu \mathrm{m}$ lower $R_{\mathrm{e}}$ in polluted boundary layers compared to separated profiles. Contact profiles were more often located in polluted boundary layers and had higher below-cloud CO concentration (27 to $29 \mathrm{ppb}$ higher), which suggests more frequent entrainment of biomass burning aerosols into the boundary layer compared to separated profiles.

3. Precipitation suppression with significantly lower precipitation intensity and precipitation formation process rates.

Separated profiles had $R_{\mathrm{p}}$ up to $0.22 \mathrm{~mm} \mathrm{~h}^{-1}$, while contact profiles had $R_{\mathrm{p}}$ up to $0.07 \mathrm{~mm} \mathrm{~h}^{-1}$. $S_{\text {AUTO }}$ and $S_{\mathrm{ACC}}$ had higher maxima for separated (up to $9.6 \times$ $10^{-10}$ and $2.2 \times 10^{-8} \mathrm{~s}^{-1}$ ) compared to contact profiles (up to $2.9 \times 10^{-10}$ and $1.2 \times 10^{-8} \mathrm{~s}^{-1}$ ).

4. Lower precipitation susceptibility, with the strongest impact in thin clouds $(H<129 \mathrm{~m})$.

Contact profiles had lower $S_{\mathrm{o}}(0.87 \pm 0.04)$ compared to separated profiles $(1.08 \pm 0.04)$. Thin clouds had the highest difference in $S_{\mathrm{o}}(-0.06 \pm 0.11$ for contact and $1.47 \pm 0.10$ for separated). Lower $S_{\mathrm{o}}$ for thin contact profiles was associated with poor correlation between $N_{\mathrm{c}}$ and $R_{\mathrm{p}}(R=-0.03)$. For separated profiles, $S_{\mathrm{o}}$ decreased with $H$ before increasing for $H>256 \mathrm{~m}$. In comparison, $S_{\mathrm{o}}$ increased with $H$ for contact profiles for $H>129 \mathrm{~m}$.

5. Statistically insignificant differences in meteorological parameters that influence $L W P / H$.
Based on ERA5 reanalysis data, LWP was correlated with SST $(R=0.22), T_{\mathrm{0}}(R=0.27)$, LTS $(R=-0.29)$, and EIS $(R=-0.31)$. Contact profiles with ERA5 LCC $>0.95$ had lower SST ( 0.01 to $1.48 \mathrm{~K}$ lower), with similar $T_{\mathrm{0}}$, LTS, and EIS compared to separated profiles. The SST differences were insignificant when profiles with LCC $<0.95$ were included in the comparison.

Three important factors affecting $S_{0}$ were discussed (Sorooshian et al., 2019): above-cloud $N_{\mathrm{a}}$, below-cloud $N_{\mathrm{a}}$, and meteorological conditions. This study analyzed ORACLES data from all three IOPs, and the first two conclusions were consistent with the analysis of ORACLES 2016 (Gupta et al., 2021). Future work will compare in situ data with $R_{\mathrm{p}}$ retrievals from APR-3 (Dzambo et al., 2021) to evaluate the sensitivity of $S_{\mathrm{o}}$ to the use of satellite retrievals of $R_{\mathrm{p}}$ (Bai et al., 2018). Vertical profiles of MSC properties will be used to evaluate satellite retrievals (Painemal and Zuidema, 2011; Zhang and Platnick, 2011) to address the uncertainties associated with satellite-based estimates of ACIs (Quaas et al., 2020). The ORACLES dataset can be combined with future investigations of marine stratocumulus to address the "lack of long-term datasets needed to provide statistical significance for a sufficiently large range of aerosol variability influencing specific cloud regimes over a range of macrophysical conditions" (Sorooshian et al., 2010). 
Appendix A: Sensitivity studies on dependence of $S_{0}$ on $H$

The base analysis examined how cloud properties varied with $H$ by separating cloud profiles into four populations of $H$ using the following endpoints: $28,129,175,256$, and $700 \mathrm{~m}$. Two sensitivity studies determine if trends describing the variation of $N_{\mathrm{c}}, R_{\mathrm{p}}$, and $S_{\mathrm{o}}$ with $H$ were sensitive to the endpoints used to sort cloud profiles into different populations.

First, cloud profiles were classified into two populations using the median $H(175 \mathrm{~m})$ to divide the populations (Table A1). The average $N_{\mathrm{c}}$ decreased, and the average $R_{\mathrm{p}}$ increased with $H$ for both contact (211 to $186 \mathrm{~cm}^{-3}$ and 0.03 to $0.07 \mathrm{~mm} \mathrm{~h}^{-1}$ ) and separated profiles (129 to $104 \mathrm{~cm}^{-3}$ and 0.07 to $0.15 \mathrm{~mm} \mathrm{~h}^{-1}$ ). $S_{\mathrm{o}}$ increased with $H$ for contact profiles from 0.53 to 1.06 and slightly decreased with $H$ for separated profiles from 1.05 to 1.02 (Table A1). The difference between $S_{\mathrm{o}}$ for contact and separated profiles was greater for thin profiles $(H<175 \mathrm{~m})$ compared to thick profiles $(H>175 \mathrm{~m})$. These results are consistent with trends using four populations but provide less detail about how $S_{\mathrm{o}}$ varies with $H$ (Fig. A1)

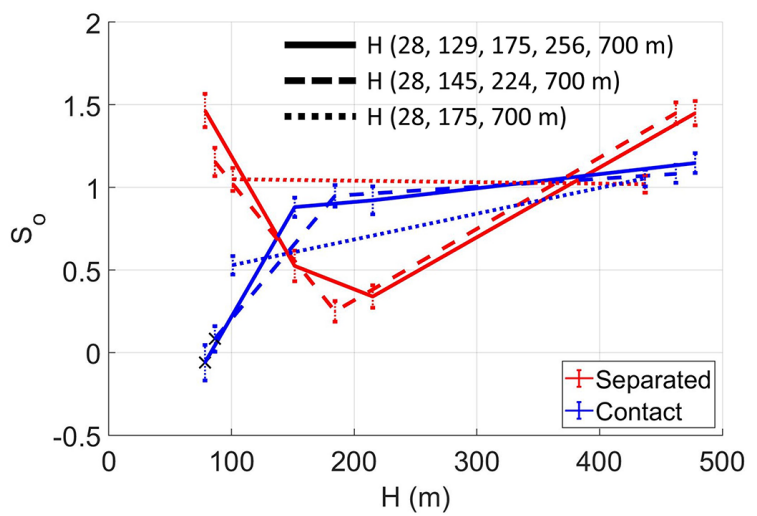

Figure A1. $S_{\mathrm{O}}$ as a function of $H$ for contact and separated profiles classified into different populations using the endpoints indicated in legend. $S_{\mathrm{O}}$ was statistically insignificant when marked with a cross.

Second, cloud profiles were classified into three populations using the terciles of $H$ (145 and $224 \mathrm{~m}$ ) (Table A1). The average $N_{\mathrm{c}}$ decreased, and the average $R_{\mathrm{p}}$ increased from the lowest to the highest $H$ for contact (231 to $187 \mathrm{~cm}^{-3}$ and 0.03 to $0.07 \mathrm{~mm} \mathrm{~h}^{-1}$ ) and separated profiles (138 to $95 \mathrm{~cm}^{-3}$ and 0.06 to $0.18 \mathrm{~mm} \mathrm{~h}^{-1}$ ). For separated profiles, $S_{\mathrm{o}}$ first decreased with $H$ from 1.15 to 0.25 before increasing to 1.45 for the highest $H$ (Fig. A1). Contact profiles had insignificant $S_{\mathrm{o}}$ for the lowest $H$, followed by $S_{\mathrm{o}}$ increasing from 0.95 to 1.08 with $H$. The results presented here are robust with regards to the number of populations used.
Table A1. $S_{\mathrm{O}} \pm$ standard error with sample size and $R$ in parentheses for contact, separated, and all profiles classified into a different number of populations.

\begin{tabular}{lrrr}
\hline$H$ bin & Contact & Separated & All profiles \\
\hline Two populations & & & \\
\hline 28 to $175 \mathrm{~m}$ & $\begin{array}{r}0.53 \pm 0.05 \\
(90,0.24)\end{array}$ & $\begin{array}{r}1.05 \pm 0.07 \\
(72,0.39)\end{array}$ & $\begin{array}{r}0.69 \pm 0.04 \\
(162,0.30)\end{array}$ \\
\hline 175 to $700 \mathrm{~m}$ & $\begin{array}{r}1.06 \pm 0.05 \\
(83,0.33)\end{array}$ & $\begin{array}{r}1.02 \pm 0.05 \\
(84,0.33)\end{array}$ & $\begin{array}{l}0.93 \pm 0.03 \\
(167,0.33)\end{array}$ \\
\hline Three populations & & & \\
\hline 28 to $145 \mathrm{~m}$ & $0.08 \pm 0.08$ & $1.15 \pm 0.09$ & $0.60 \pm 0.05$ \\
& $(67,0.04)$ & $(41,0.45)$ & $(108,0.26)$ \\
\hline 145 to $224 \mathrm{~m}$ & $0.95 \pm 0.07$ & $0.25 \pm 0.06$ & $0.60 \pm 0.04$ \\
& $(51,0.34)$ & $(60,0.11)$ & $(111,0.25)$ \\
\hline 224 to $700 \mathrm{~m}$ & $1.08 \pm 0.05$ & $1.45 \pm 0.06$ & $1.05 \pm 0.04$ \\
& $(55,0.34)$ & $(55,0.41)$ & $(110,0.37)$ \\
\hline
\end{tabular}

Appendix B: Sensitivity studies on dependence of $S_{0}$ on $R_{\mathrm{p}}$

Another sensitivity study examined the $R_{\mathrm{p}}$ threshold used for cloud profiles included while calculating $S_{0}$. The average $S_{0}$ decreased if weakly precipitating clouds with low $R_{\mathrm{p}}$ were excluded (Fig. B1, Table B1). It is possible that this was due to the higher $N_{\mathrm{a}}$ and $N_{\mathrm{c}}$ associated with weakly precipitating clouds. The exclusion of weakly precipitating clouds provides biased trends in $S_{\mathrm{o}}$ since these clouds could have undergone precipitation suppression already. Conversely, strongly precipitating clouds were associated with cleaner conditions and lower $N_{\mathrm{a}}$ and $N_{\mathrm{c}}$. The exclusion of strongly precipitating clouds also leads to a decrease in the average $S_{\mathrm{o}}$ (Fig. B2, Table B1).

The occurrence of wet scavenging below strongly precipitating clouds (Duong et al., 2011) results in lower belowcloud $N_{\mathrm{a}}$ (and subsequently $N_{\mathrm{c}}$ ). Higher susceptibility to precipitation suppression for cleaner, strongly precipitating clouds would explain the increase in the average $S_{0}$. This is consistent with observations of $S_{\mathrm{o}}$ using different $R_{\mathrm{p}}$ thresholds (see Fig B1, Jung et al., 2016) and hypotheses regarding the impact of different $N_{\mathrm{a}}$ on $S_{\mathrm{o}}$ (Duong et al., 2011; Fig. 11, Jung et al., 2016). 
Table B1. $S_{\mathrm{O}} \pm$ standard error with sample size and $R$ in parentheses for contact, separated, and all profiles with $R_{\mathrm{p}}$ above a certain threshold.

\begin{tabular}{|c|c|c|c|}
\hline$H$ bin & Contact & Separated & All profiles \\
\hline \multicolumn{4}{|c|}{$R_{\mathrm{p}}>10^{-3} \mathrm{~mm} \mathrm{~h}^{-1}$} \\
\hline All & $\begin{array}{r}0.88 \pm 0.03 \\
(173,0.34)\end{array}$ & $\begin{array}{r}0.95 \pm 0.04 \\
(156,0.36)\end{array}$ & $\begin{array}{r}0.84 \pm 0.02 \\
(329,0.37)\end{array}$ \\
\hline 28 to $129 \mathrm{~m}$ & $\begin{array}{r}0.03 \pm 0.10 \\
(52,0.02)\end{array}$ & $\begin{array}{r}1.41 \pm 0.09 \\
(30,0.61)\end{array}$ & $\begin{array}{r}0.71 \pm 0.07 \\
(82,0.33)\end{array}$ \\
\hline 129 to $175 \mathrm{~m}$ & $\begin{array}{r}0.94 \pm 0.05 \\
(38,0.49)\end{array}$ & $\begin{array}{r}0.64 \pm 0.09 \\
(42,0.27)\end{array}$ & $\begin{array}{r}0.78 \pm 0.04 \\
(80,0.40)\end{array}$ \\
\hline 175 to $256 \mathrm{~m}$ & $\begin{array}{r}0.78 \pm 0.07 \\
(41,0.30)\end{array}$ & $\begin{array}{r}0.21 \pm 0.06 \\
(44,0.10)\end{array}$ & $\begin{array}{r}0.38 \pm 0.04 \\
(85,0.18)\end{array}$ \\
\hline 256 to $700 \mathrm{~m}$ & $\begin{array}{r}1.11 \pm 0.06 \\
(42,0.38)\end{array}$ & $\begin{array}{r}1.18 \pm 0.07 \\
(40,0.39)\end{array}$ & $\begin{array}{r}1.06 \pm 0.04 \\
(82,0.42)\end{array}$ \\
\hline \multicolumn{4}{|c|}{$R_{\mathrm{p}}>10^{-2} \mathrm{~mm} \mathrm{~h}^{-1}$} \\
\hline All & $\begin{array}{r}0.49 \pm 0.03 \\
(173,0.27)\end{array}$ & $\begin{array}{r}0.76 \pm 0.03 \\
(156,0.38)\end{array}$ & $\begin{array}{r}0.61 \pm 0.02 \\
(329,0.35)\end{array}$ \\
\hline 28 to $129 \mathrm{~m}$ & $\begin{array}{r}0.01 \pm 0.08 \\
(52,0.01)\end{array}$ & $\begin{array}{r}0.97 \pm 0.10 \\
(30,0.57)\end{array}$ & $\begin{array}{r}0.48 \pm 0.06 \\
(82,0.36)\end{array}$ \\
\hline 129 to $175 \mathrm{~m}$ & $\begin{array}{r}0.70 \pm 0.04 \\
(38,0.53)\end{array}$ & $\begin{array}{r}0.53 \pm 0.08 \\
(42,0.29)\end{array}$ & $\begin{array}{r}0.66 \pm 0.04 \\
(80,0.44)\end{array}$ \\
\hline 175 to $256 \mathrm{~m}$ & $\begin{array}{r}0.62 \pm 0.06 \\
(41,0.31)\end{array}$ & $\begin{array}{r}0.48 \pm 0.05 \\
\quad(44,0.31)\end{array}$ & $\begin{array}{r}0.47 \pm 0.04 \\
(85,0.28)\end{array}$ \\
\hline 256 to $700 \mathrm{~m}$ & $\begin{array}{r}0.37 \pm 0.05 \\
(42,0.19)\end{array}$ & $\begin{array}{r}0.78 \pm 0.06 \\
(40,0.33)\end{array}$ & $\begin{array}{r}0.60 \pm 0.03 \\
(82,0.32)\end{array}$ \\
\hline
\end{tabular}

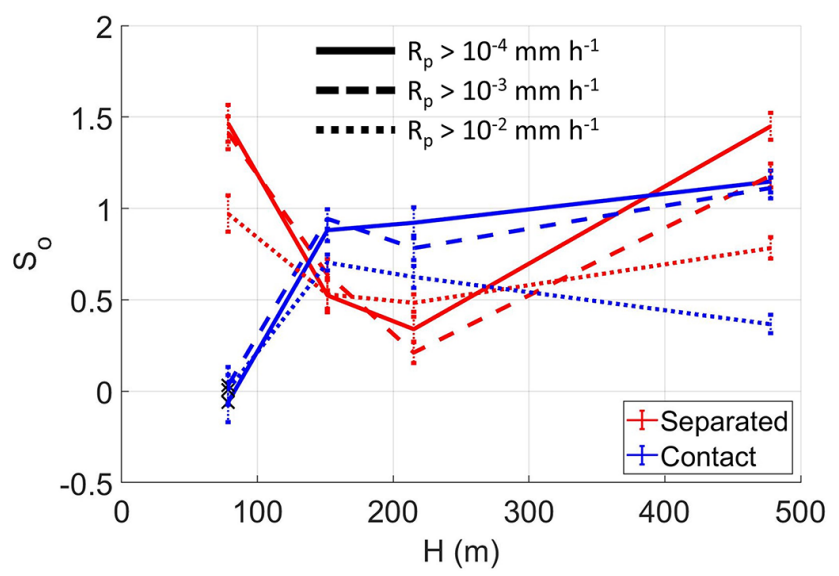

Figure B1. $S_{\mathrm{O}}$ as a function of $H$ for contact and separated profiles, with $R_{\mathrm{p}}$ greater than the thresholds indicated in legend. $S_{\mathrm{O}}$ was statistically insignificant when marked with a cross.

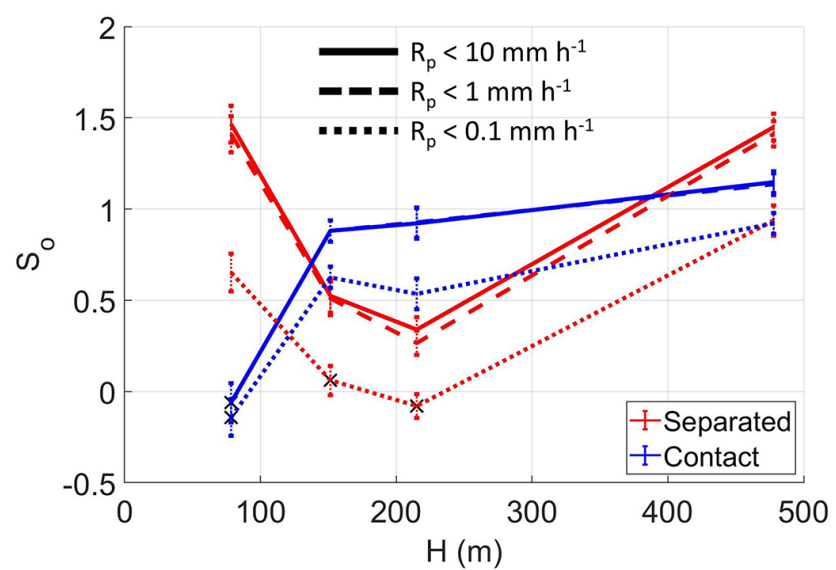

Figure B2. $S_{\mathrm{O}}$ as a function of $H$ for contact and separated profiles, with $R_{\mathrm{p}}$ less than the thresholds indicated in legend. $S_{\mathrm{o}}$ was statistically insignificant when marked with a cross.

\section{Appendix C: Dependence of $S_{0}$ on the definition of clean and polluted boundary layers}

The number of cloud profiles classified into the S-L, C-L, $\mathrm{S}-\mathrm{H}$, and $\mathrm{C}-\mathrm{H}$ regimes varied depending on the below-cloud $N_{\mathrm{a}}$ threshold used to define a low $N_{\mathrm{a}}$ or clean boundary layer. For the threshold used in the base analysis $\left(350 \mathrm{~cm}^{-3}\right)$, contact profiles were more often located in polluted boundary layers (131 out of 171 profiles classified as $\mathrm{C}-\mathrm{H}$ ) while separated profiles were more often located in clean boundary layers (108 out of 148 profiles classified as S-L). The comparisons between $S_{\mathrm{o}}$ in clean and polluted boundary layers varied with the threshold used.

As a sensitivity study, a lower threshold was used to define a clean boundary layer $\left(300 \mathrm{~cm}^{-3}\right)$. For this case, the $\mathrm{C}$-L regime had no profiles in the population with the lowest $H(H<129 \mathrm{~m})$ when four populations of profiles were used to examine the dependence of $S_{\mathrm{o}}$ on $H$. Two out of the other three populations had an insignificant value for $S_{\mathrm{o}}$ due to poor and statistically insignificant correlations between $N_{\mathrm{c}}$ and $R_{\mathrm{p}}$ (Table $\left.\mathrm{C} 1\right)$. This was associated with a low sample size for the populations (six each). A second sensitivity study used a higher threshold to define a clean boundary layer $\left(400 \mathrm{~cm}^{-3}\right)$. For this case, the S-H regime has insignificant $S_{\mathrm{o}}$ for three out of the four populations of $H$ and the remaining population had a small sample size (three profiles) (Table C1). The base analysis using a threshold of $350 \mathrm{~cm}^{-3}$ to define a clean boundary layer was used to compare $S_{0}$ values that represent a larger number of cloud profiles. 
Table C1. $S_{\mathrm{o}} \pm$ standard error with sample size and $R$ in parentheses for regimes defined in text and different thresholds to define a low $N_{\mathrm{a}}$ boundary layer. The use of italics denotes the statistical insignificance of $S_{0}$.

\begin{tabular}{lrrrr}
\hline$H$ & S-L & S-H & C-L & C-H \\
\hline Low $N_{\mathrm{a}}=300 \mathrm{~cm}^{-3}$ & & & \\
\hline All & $1.37 \pm 0.06$ & $\begin{array}{r}0.45 \pm 0.06 \\
(52,0.17)\end{array}$ & $\begin{array}{r}0.29 \pm 0.10 \\
(21,0.10)\end{array}$ & $\begin{array}{r}0.84 \pm 0.04 \\
(150,0.29)\end{array}$ \\
\hline 28 to & $1.20 \pm 0.16$ & $0.38 \pm 0.13$ & $\mathrm{NaN}$ & $-0.06 \pm 0.11$ \\
$129 \mathrm{~m}$ & $(19,0.44)$ & $(10,0.25)$ & $(0, \mathrm{NaN})$ & $(52,-0.03)$ \\
\hline 129 to & $0.68 \pm 0.13$ & $0.56 \pm 0.16$ & $0.02 \pm 0.15$ & $0.86 \pm 0.07$ \\
$175 \mathrm{~m}$ & $(21,0.26)$ & $(15,0.20)$ & $(6,0.01)$ & $(30,0.41)$ \\
\hline 175 to & $0.70 \pm 0.10$ & $0.07 \pm 0.10$ & $0.44 \pm 0.17$ & $1.04 \pm 0.10$ \\
$256 \mathrm{~m}$ & $(31,0.24)$ & $(12,0.03)$ & $(9,0.15)$ & $(32,0.30)$ \\
\hline 256 to & $2.03 \pm 0.10$ & $0.40 \pm 0.10$ & $-0.09 \pm 0.17$ & $1.13 \pm 0.07$ \\
$700 \mathrm{~m}$ & $(25,0.55)$ & $(15,0.12)$ & $(6,-0.03)$ & $(36,0.36)$ \\
\hline Low $N_{\mathrm{a}}=400 \mathrm{~cm}{ }^{-3}$ & & & \\
\hline All & $1.12 \pm 0.05$ & $0.37 \pm 0.09$ & $1.11 \pm 0.05$ & $0.25 \pm 0.06$ \\
& $(125,0.36)$ & $(23,0.16)$ & $(64,0.39)$ & $(107,0.08)$ \\
\hline 28 to & $1.04 \pm 0.13$ & $-0.20 \pm 0.21$ & $0.51 \pm 0.22$ & $-0.33 \pm 0.13$ \\
$129 \mathrm{~m}$ & $(23,0.43)$ & $(6,-0.11)$ & $(11,0.21)$ & $(41,-0.14)$ \\
\hline 129 to & $0.81 \pm 0.11$ & $0.02 \pm 0.19$ & $0.90 \pm 0.10$ & $0.22 \pm 0.09$ \\
$175 \mathrm{~m}$ & $(30,0.30)$ & $(6,0.01)$ & $(12,0.43)$ & $(24,0.10)$ \\
\hline 175 to & $0.53 \pm 0.09$ & $0.12 \pm 0.12$ & $0.84 \pm 0.09$ & $0.53 \pm 0.19$ \\
$256 \mathrm{~m}$ & $(35,0.19)$ & $(8,0.06)$ & $(24,0.30)$ & $(17,0.12)$ \\
\hline 256 to & $1.42 \pm 0.07$ & $1.10 \pm 0.42$ & $1.52 \pm 0.08$ & $0.47 \pm 0.09$ \\
$700 \mathrm{~m}$ & $(37,0.41)$ & $(3,0.25)$ & $(17,0.50)$ & $(25,0.13)$ \\
\hline & \multicolumn{3}{r}{} &
\end{tabular}

Appendix D: Sensitivity of $S_{0}$ to the use of CAS data from ORACLES 2016

Given the differences between the CAS and PDI $N_{\mathrm{c}}$ and LWC for droplets with $D<50 \mu \mathrm{m}$ during ORACLES 2016 (see Supplement), sensitivity tests were performed by first excluding ORACLES 2016 data and second by using PDI data to represent ORACLES 2016 size distributions for $D<50 \mu \mathrm{m}$ in the $S_{\mathrm{o}}$ calculations. These sensitivity tests resulted in minor changes in the trends of $S_{0}$ versus $H$ (Fig. D1), along with average changes in the magnitude of $S_{\mathrm{o}}$ up to 0.05 (Table D1). The noted changes suggest that the discussion of trends in $S_{\mathrm{O}}$ described in this study is robust as it relates to the inclusion of ORACLES 2016 data and the use of CAS data for the deployment. Since the 2016 deployment contributed about a third of the ORACLES measurements, data from the 2016 deployment were included in the study so as not to reduce the size of the dataset.
The slight decrease in $S_{\mathrm{o}}$ for thick clouds $(H>256 \mathrm{~m})$ upon removal of ORACLES 2016 data is associated with a decrease in the number of thick clouds (Table D1). The use of PDI data resulted in minor changes because $S_{\mathrm{o}}$ primarily depends on $N_{\mathrm{c}}$ and $R_{\mathrm{p}}$. The CAS and PDI datasets had small differences in the average $N_{\mathrm{c}}(95 \%$ confidence intervals of 9 to $12 \mathrm{~cm}^{-3}$ ), and $R_{\mathrm{p}}$ was calculated using droplets with $D>50 \mu \mathrm{m}$, which do not include contributions from either the CAS or the PDI. The documentation of differences between the ORACLES cloud probes (see Supplement) highlights the measurement uncertainties associated with the cloud probe datasets.

Table D1. $S_{\mathrm{O}} \pm$ standard error for all profiles, with sample size and $R$ in parentheses.

\begin{tabular}{lrrr}
\hline$H$ & $\begin{array}{r}\text { CAS data } \\
\text { from 2016 }\end{array}$ & $\begin{array}{r}\text { No data } \\
\text { from 2016 }\end{array}$ & $\begin{array}{r}\text { PDI data } \\
\text { from 2016 }\end{array}$ \\
\hline All & $\begin{array}{r}0.88 \pm 0.03 \\
(329,0.33)\end{array}$ & $\begin{array}{r}0.83 \pm 0.03 \\
(258,0.33)\end{array}$ & $\begin{array}{r}0.90 \pm 0.02 \\
(329,0.35)\end{array}$ \\
\hline 28 to $129 \mathrm{~m}$ & $\begin{array}{r}0.67 \pm 0.07 \\
(82,0.28)\end{array}$ & $\begin{array}{r}0.58 \pm 0.07 \\
(80,0.26)\end{array}$ & $\begin{array}{r}0.68 \pm 0.07 \\
(84,0.29)\end{array}$ \\
\hline 129 to $175 \mathrm{~m}$ & $\begin{array}{r}0.68 \pm 0.05 \\
(80,0.32)\end{array}$ & $\begin{array}{r}0.73 \pm 0.05 \\
(63,0.35)\end{array}$ & $\begin{array}{r}0.73 \pm 0.05 \\
(79,0.35)\end{array}$ \\
\hline 175 to $256 \mathrm{~m}$ & $\begin{array}{r}0.54 \pm 0.05 \\
(85,0.20)\end{array}$ & $\begin{array}{r}0.84 \pm 0.06 \\
(58,0.31)\end{array}$ & $\begin{array}{r}0.71 \pm 0.05 \\
(86,0.26)\end{array}$ \\
\hline 256 to $700 \mathrm{~m}$ & $\begin{array}{r}1.13 \pm 0.04 \\
(82,0.40)\end{array}$ & $\begin{array}{c}0.75 \pm 0.04 \\
(57,0.30)\end{array}$ & $\begin{array}{r}1.10 \pm 0.04 \\
(80,0.41)\end{array}$ \\
\hline
\end{tabular}



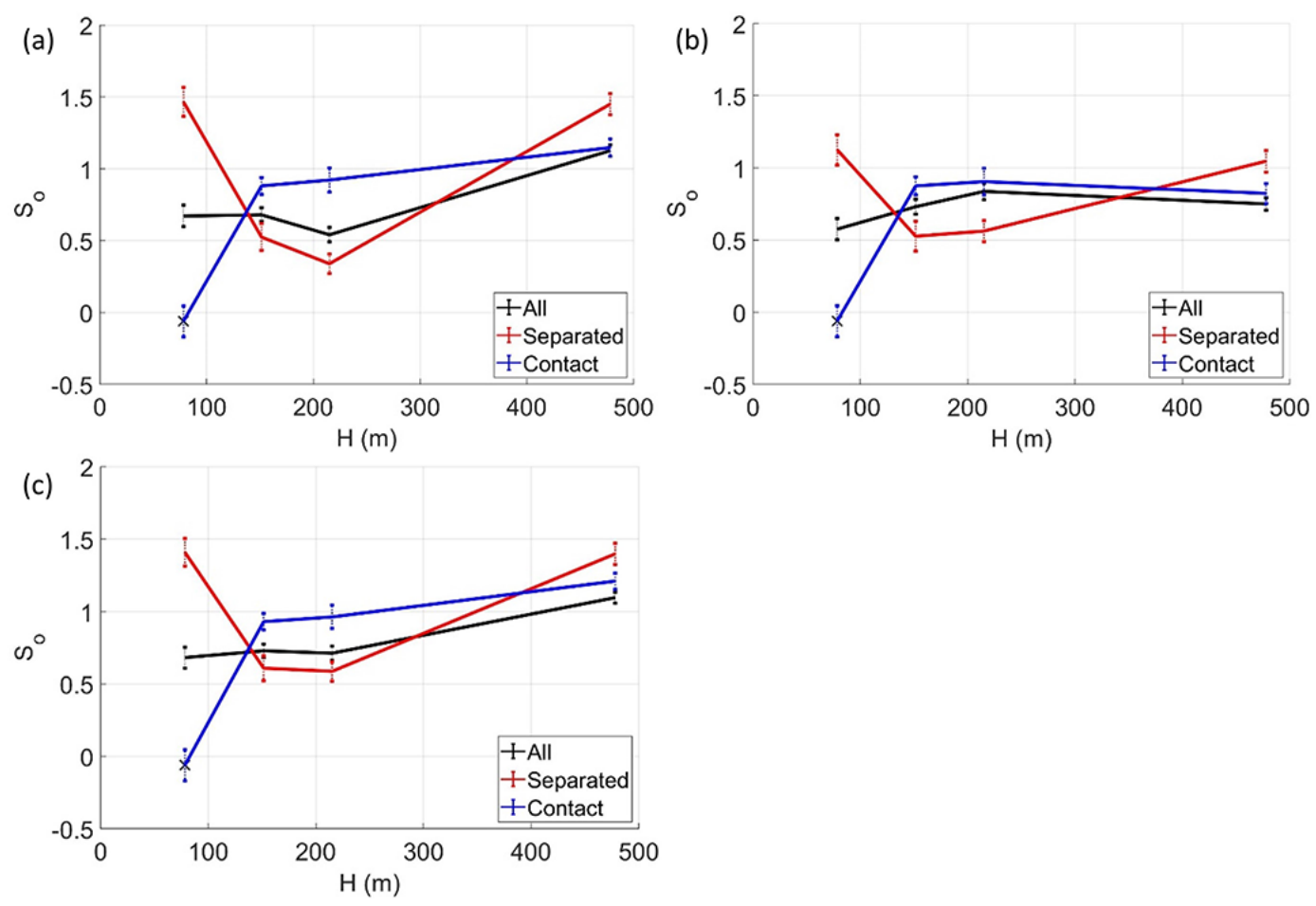

Figure D1. $S_{\mathrm{o}}$ as a function of $H$ (error bars extend to standard error from regression model) using (a) CAS data, (b) no data, or (c) PDI data from ORACLES 2016.

Code availability. University of Illinois/Oklahoma Optical Array Probe (OAP) Processing Software is available at https://doi.org/10.5281/zenodo.1285969 (McFarquhar et al., 2018). The Airborne Data Processing and Analysis software package is available at https://doi.org/10.5281/zenodo.3733448 (Delene et al., 2020).

Data availability. All ORACLES data are accessible via the digital object identifiers provided under ORACLES Science Team references: https://doi.org/10.5067/Suborbital/ORACLES/P3/2018_V2 (ORACLES Science Team, 2020a), https://doi.org/10.5067/Suborbital/ORACLES/P3/2017_V2 (ORACLES Science Team, 2020b), and https://doi.org/10.5067/Suborbital/ORACLES/P3/2016_V2 (ORACLES Science Team, 2020c). ERA5 data were obtained from the Climate Data Store (last access: 18 May 2021): https://cds.climate.copernicus.eu/cdsapp\#!/home (CDS, 2017; Hersbach et al., 2020).

Supplement. The supplement related to this article is available online at: https://doi.org/10.5194/acp-22-2769-2022-supplement.
Author contributions. GMM and MRP worked with other investigators to design the ORACLES project and flight campaigns. SG designed the study with guidance from GMM. SG analyzed the data with inputs from GMM, JRO'B, and MRP. JRO'B and DJD processed PCASP data and cloud probe data, conducted data quality tests, and some of the data comparisons between cloud probes. SG processed 2D-S and HVPS-3 data and conducted some of the data comparisons between cloud probes. JDSG processed PDI data. GMM and MRP acquired funding. All authors were involved in data collection during ORACLES. SG wrote the manuscript with guidance from GMM and reviews from all authors.

Competing interests. The contact author has declared that neither they nor their co-authors have any competing interests.

Disclaimer. Publisher's note: Copernicus Publications remains neutral with regard to jurisdictional claims in published maps and institutional affiliations.

Special issue statement. This article is part of the special issue "New observations and related modeling studies of the aerosolcloud-climate system in the Southeast Atlantic and southern Africa regions (ACP/AMT inter-journal SI)". This article is not associated with a conference. 
Acknowledgements. The authors thank Yohei Shinozuka for providing merged instrument data files for the ORACLES field campaign. We acknowledge the entire ORACLES science team for their assistance with data acquisition, analysis, and interpretation. We thank the NASA Ames Earth Science Project Office and the NASA P-3B flight/maintenance crew for logistical and aircraft support. Some of the computing for this project was performed at the OU Supercomputing Center for Education \& Research (OSCER) at the University of Oklahoma (OU).

Financial support. ORACLES is funded by NASA Earth Venture Suborbital-2 (grant no. NNH13ZDA001N-EVS2). Siddhant Gupta was supported by NASA headquarters under the NASA Earth and Space Science Fellowship (grant nos. NNX15AF93G and NNX16A018H). Greg M. McFarquhar and Siddhant Gupta were supported by NASA (grant no. 80NSSC18K0222).

Review statement. This paper was edited by J. M. Haywood and reviewed by three anonymous referees.

\section{References}

Abel, S. J. and Boutle, I. A.: An improved representation of the raindrop size distribution for single-moment microphysics schemes, Q. J. Roy. Meteor. Soc., 138, 2151-2162, https://doi.org/10.1002/qj.1949, 2012.

Ackerman, A. S., Kirkpatrick, M. P., Stevens, D. E., and Toon, O. B.: The impact of humidity above stratiform clouds on indirect aerosol climate forcing, Nature, 432, 1014-1017, 2004.

Adebiyi, A. A. and Zuidema, P.: The role of the southern African easterly jet in modifying the southeast Atlantic aerosol and cloud environments, Q. J. Roy. Meteor. Soc., 142, 1574-1589, https://doi.org/10.1002/qj.2765, 2016.

Ahlgrimm, M. and Forbes, R.: Improving the Representation of Low Clouds and Drizzle in the ECMWF Model Based on ARM Observations from the Azores, Mon. Weather Rev., 142, 668685, https://doi.org/10.1175/mwr-d-13-00153.1, 2014.

Ahlgrimm, M., Randall, D. A., and Kohler, M.: Evaluating cloud frequency of occurrence and cloud-top height using spaceborne lidar observations, Mon. Weather Rev., 137, 4225-4237, 2009.

Albrecht, B.: Aerosols, Cloud Microphysics, and Fractional Cloudiness, Science, 245, 1227-1230, 1989.

Bai, H., Gong, C., Wang, M., Zhang, Z., and L'Ecuyer, T.: Estimating precipitation susceptibility in warm marine clouds using multi-sensor aerosol and cloud products from A-Train satellites, Atmos. Chem. Phys., 18, 1763-1783, https://doi.org/10.5194/acp-18-1763-2018, 2018.

Baumgardner, D., Jonsson, H., Dawson, W., Connor, D. O., and Newton, R.: The cloud, aerosol and precipitation spectrometer (CAPS): A new instrument for cloud investigations, Atmos. Res., 59, 59-60, 2001.

Baumgardner, D., Abel, S. J., Axisa, D., Cotton, R., Crosier, J., Field, P., Gurganus, C., Heymsfield, A., Korolev, A., Kraemer, M., Lawson, P., McFarquhar, G., Ulanowski, Z., and Um, J.: Cloud ice properties: in situ measurement challenges, Meteor. Mon., 58, 9.1-9.23,
https://doi.org/10.1175/AMSMONOGRAPHS-D-16-0011.1, 2017.

Behrangi, A., Stephens, G., Adler, R. F., Huffman, G. J., Lambrigtsen, B., and Lebsock, M.: An update on the oceanic precipitation rate and its zonal distribution in light of advanced observations from space, J. Climate, 27, 3957-3965, https://doi.org/10.1175/JCLI-D-13-00679.1, 2014.

Bennartz, R.: Global assessment of marine boundary layer cloud droplet number concentration from satellite, J. Geophys. Res., 112, D02201, https://doi.org/10.1029/2006JD007547, 2007.

Boers, R., Acarreta, J. R., and Gras, J. L.: Satellite monitoring of the first indirect aerosol effect: Retrieval of the droplet concentration of water clouds, J. Geophys. Res.-Atmos., 111, D22208, https://doi.org/10.1029/2005JD006838, 2006.

Bony, S. and Dufrense, J.-L.: Marine boundary layer clouds at the heart of tropical feedback uncertainties in climate models, Geophys. Res. Lett., 32, L20806, https://doi.org/10.1029/2005GL023851, 2005.

Boucher, O., Randall, D., Artaxo, P., Bretherton, C., Feingold, G., Forster, P., Kerminen, V.-M., Kondo, Y., Liao, H., Lohmann, U., Rasch, P., Satheesh, S. K., Sherwood, S., Stevens, B., and Zhang, X. Y.: Clouds and Aerosols, in: Climate Change 2013: The Physical Science Basis, Contribution of Working Group I to the Fifth Assessment Report of the Intergovernmental Panel on Climate Change, edited by: Stocker, T. F., Qin, D., Plattner, G.-K., Tignor, M., Allen, S. K., Boschung, J., Nauels, A., Xia, Y., Bex, V., and Midgley, P. M., Cambridge University Press, Cambridge, United Kingdom and New York, NY, USA, 571-657, 2013.

Boutle, I. A., Abel, S. J., Hill, P. G., and Morcrette, C. J.: Spatial variability of liquid cloud and rain: observations and microphysical effects, Q. J. Roy. Meteor. Soc., 140, 583-594, https://doi.org/10.1002/qj.2140, 2014.

Braun, R. A., Dadashazar, H., MacDonald, A. B., Crosbie, E., Jonsson, H. H., Woods, R. K., Flagan, R. C., Seinfeld, J. H., and Sorooshian, A.: Cloud Adiabaticity and Its Relationship to Marine Stratocumulus Characteristics Over the Northeast Pacific Ocean, J. Geophys. Res.-Atmos., 123, 13790-13806, https://doi.org/10.1029/2018JD029287, 2018.

Brenguier, J.-L., Pawlowska, H., Schuller, L., Preusker, R., Fischer, J., and Fouquart, Y.: Radiative properties of boundary layer clouds: Droplet effective radius versus number concentration, J. Atmos. Sci., 57, 803-821, 2000.

Cai, Y., Snider, J. R., and Wechsler, P.: Calibration of the passive cavity aerosol spectrometer probe for airborne determination of the size distribution, Atmos. Meas. Tech., 6, 2349-2358, https://doi.org/10.5194/amt-6-2349-2013, 2013.

CDS: ERA5 Fifth generation of ECMWF atmospheric reanalyses of the global climate, CDS [data set], https://cds.climate. copernicus.eu/cdsapp\#!/home (last access: 26 November 2019), 2017.

Chen, Y.-C., Christensen, M. W., Stephens, G. L., and Seinfeld, J. H.: Satellite-based estimate of global aerosol-cloud radiative forcing by marine warm clouds, Nat. Geosci., 7, 643-646, https://doi.org/10.1038/ngeo2214, 2014.

Christensen, M. W. and Stephens, G. L.: Microphysical and macrophysical responses of marine stratocumulus polluted by underlying ships. Part 2: Impacts of haze on precipitating clouds, J. Geophys. Res., 117, D11203, https://doi.org/10.1029/2011JD017125, 2012. 
Chuang, P. Y., Saw, E. W., Small, J. D., Shaw, R. A., Sipperley, C. M., Payne, G. A., and Bachalo, W.: Airborne Phase 495 Doppler Interferometry for Cloud Microphysical Measurements, Aerosol Sci. Technol., 42, 685-703, 2008.

Cochrane, S. P., Schmidt, K. S., Chen, H., Pilewskie, P., Kittelman, S., Redemann, J., LeBlanc, S., Pistone, K., Kacenelenbogen, M., Segal Rozenhaimer, M., Shinozuka, Y., Flynn, C., Platnick, S., Meyer, K., Ferrare, R., Burton, S., Hostetler, C., Howell, S., Freitag, S., Dobracki, A., and Doherty, S.: Above-cloud aerosol radiative effects based on ORACLES 2016 and ORACLES 2017 aircraft experiments, Atmos. Meas. Tech., 12, 65056528, https://doi.org/10.5194/amt-12-6505-2019, 2019.

Dadashazar, H., Wang, Z., Crosbie, E., Brunke, M., Zeng, X., Jonsson, H., Woods, R. K., Flagan, R. C., Seinfeld, J. H., and Sorooshian, A.: Relationships between giant sea salt particles and clouds inferred from aircraft physicochemical data, J. Geophys. Res.-Atmos., 122, 3421-3434, https://doi.org/10.1002/2016JD026019, 2017.

Delene, D. J.: Airborne Data Processing and Analysis Software Package, Earth Sci. Inform., 4, 29-44, 2011.

Delene, D. J., Skow, A., O’Brien, J., Gapp, N., Wagner, S., Hibert, K., Sand, K., and Sova, G.: Airborne Data Processing and Analysis Software Package (Version 3981), Zenodo [code], https://doi.org/10.5281/zenodo.3733448, 2020.

Devasthale, A. and Thomas, M. A.: A global survey of aerosol-liquid water cloud overlap based on four years of CALIPSO-CALIOP data, Atmos. Chem. Phys., 11, 1143-1154, https://doi.org/10.5194/acp-11-1143-2011, 2011.

Diamond, M. S., Dobracki, A., Freitag, S., Small Griswold, J. D., Heikkila, A., Howell, S. G., Kacarab, M. E., Podolske, J. R., Saide, P. E., and Wood, R.: Time-dependent entrainment of smoke presents an observational challenge for assessing aerosolcloud interactions over the southeast Atlantic Ocean, Atmos. Chem. Phys., 18, 14623-14636, https://doi.org/10.5194/acp-1814623-2018, 2018.

Doherty, S. J., Saide, P. E., Zuidema, P., Shinozuka, Y., Ferrada, G. A., Gordon, H., Mallet, M., Meyer, K., Painemal, D., Howell, S. G., Freitag, S., Dobracki, A., Podolske, J. R., Burton, S. P., Ferrare, R. A., Howes, C., Nabat, P., Carmichael, G. R., da Silva, A., Pistone, K., Chang, I., Gao, L., Wood, R., and Redemann, J.: Modeled and observed properties related to the direct aerosol radiative effect of biomass burning aerosol over the southeastern Atlantic, Atmos. Chem. Phys., 22, 1-46, https://doi.org/10.5194/acp-22-1-2022, 2022.

Douglas, A. and L'Ecuyer, T.: Quantifying variations in shortwave aerosol-cloud-radiation interactions using local meteorology and cloud state constraints, Atmos. Chem. Phys., 19, 62516268, https://doi.org/10.5194/acp-19-6251-2019, 2019.

Douglas, A. and L'Ecuyer, T.: Quantifying cloud adjustments and the radiative forcing due to aerosol-cloud interactions in satellite observations of warm marine clouds, Atmos. Chem. Phys., 20, 6225-6241, https://doi.org/10.5194/acp-20-6225-2020, 2020.

Duong, H. T., Sorooshian, A., and Feingold, G.: Investigating potential biases in observed and modeled metrics of aerosol-cloudprecipitation interactions, Atmos. Chem. Phys., 11, 4027-4037, https://doi.org/10.5194/acp-11-4027-2011, 2011.

Dzambo, A. M., L'Ecuyer, T. S., Sy, O. O., and Tanelli, S.: The Observed Structure and Precipitation Characteristics of Southeast Atlantic Stratocumulus from Airborne Radar during OR-
ACLES 2016-17, J. Appl. Meteor. Climatol., 58, 2197-2215, https://doi.org/10.1175/JAMC-D-19-0032.1, 2019.

Dzambo, A. M., L'Ecuyer, T., Sinclair, K., van Diedenhoven, B., Gupta, S., McFarquhar, G., O'Brien, J. R., Cairns, B., Wasilewski, A. P., and Alexandrov, M.: Joint cloud water path and rainwater path retrievals from airborne ORACLES observations, Atmos. Chem. Phys., 21, 5513-5532, https://doi.org/10.5194/acp-21-5513-2021, 2021.

Eastman, R., Warren, S. G., and Hahn, C. J.: Variations in Cloud Cover and Cloud Types over the Ocean from Surface Observations, 1954-2008, J. Climate, 24, 5914-5934, https://doi.org/10.1175/2011JCLI3972.1, 2011.

ECMWF: IFS Documentation, IFS Documentation CY47R1: IFS Documentation CY47R1 - Part IV: Physical Processes, https://doi.org/10.21957/cpmkqvhja, 2020.

Feingold, G. and Siebert, H.: Cloud - Aerosol Interactions from the Micro to the Cloud Scale, from the Strungmann Forum Report, Clouds in the Perturbed Climate System: Their Relationship to Energy Balance, Atmospheric Dynamics, and Precipitation, 2, edited by: Heintzenberg, J. and Charlson, R. J., MIT Press, ISBN 978-0-262-01287-4, 2009.

Gettelman, A., Morrison, H., Terai, C. R., and Wood, R.: Microphysical process rates and global aerosol-cloud interactions, Atmos. Chem. Phys., 13, 9855-9867, https://doi.org/10.5194/acp13-9855-2013, 2013.

Geoffroy, O., Brenguier, J.-L., and Sandu, I.: Relationship between drizzle rate, liquid water path and droplet concentration at the scale of a stratocumulus cloud system, Atmos. Chem. Phys., 8, 4641-4654, https://doi.org/10.5194/acp-8-4641-2008, 2008.

Geoffroy, O., Brenguier, J.-L., and Burnet, F.: Parametric representation of the cloud droplet spectra for LES warm bulk microphysical schemes, Atmos. Chem. Phys., 10, 4835-4848, https://doi.org/10.5194/acp-10-4835-2010, 2010.

Gordon, H., Field, P. R., Abel, S. J., Dalvi, M., Grosvenor, D. P., Hill, A. A., Johnson, B. T., Miltenberger, A. K., Yoshioka, M., and Carslaw, K. S.: Large simulated radiative effects of smoke in the south-east Atlantic, Atmos. Chem. Phys., 18, 15261-15289, https://doi.org/10.5194/acp-18-15261-2018, 2018.

Gryspeerdt, E., Goren, T., Sourdeval, O., Quaas, J., Mülmenstädt, J., Dipu, S., Unglaub, C., Gettelman, A., and Christensen, M.: Constraining the aerosol influence on cloud liquid water path, Atmos. Chem. Phys., 19, 5331-5347, https://doi.org/10.5194/acp19-5331-2019, 2019.

Gui, K., Che, H., Zheng, Y., Zhao, H., Yao, W., Li, L., Zhang, L., Wang, H., Wang, Y., and Zhang, X.: Three-dimensional climatology, trends, and meteorological drivers of global and regional tropospheric type-dependent aerosols: insights from 13 years (2007-2019) of CALIOP observations, Atmos. Chem. Phys., 21, 15309-15336, https://doi.org/10.5194/acp-21-153092021, 2021.

Gupta, S., McFarquhar, G. M., O’Brien, J. R., Delene, D. J., Poellot, M. R., Dobracki, A., Podolske, J. R., Redemann, J., LeBlanc, S. E., Segal-Rozenhaimer, M., and Pistone, K.: Impact of the variability in vertical separation between biomass burning aerosols and marine stratocumulus on cloud microphysical properties over the Southeast Atlantic, Atmos. Chem. Phys., 21, 46154635, https://doi.org/10.5194/acp-21-4615-2021, 2021.

Hannay, C., Williamson, D., Hack, J., Kiehl, J., Olson, J., Klein, S., Bretherton, C., and Kohler, M.: Evaluation of forecasted south- 
east pacific stratocumulus in the NCAR, GFDL, and ECMWF Models, J. Climate, 22, 2871-2889, 2009.

Hansen, J. and Travis, L. D.: Light scattering in planetary atmospheres, Space Sci. Rev., 16, 527-610, 1974

Hersbach, H., Bell, B., Berrisford, P., Hirahara, S., Horányi, A., Muñoz-Sabater, J., Nicolas, J., Peubey, C., Radu, R., Schepers, D., Simmons, A., Soci, C., Abdalla, S., Abellan, X., Balsamo, G., Bechtold, P., Biavati, G., Bidlot, J., Bonavita, M., De Chiara, G., Dahlgren, P., Dee, D., Diamantakis, M., Dragani, R., Flemming, J., Forbes, R., Fuentes, M., Geer, A., Haimberger, L., Healy, S., Hogan, R. J., Hólm, E., Janisková, M., Keeley, S., Laloyaux, P., Lopez, P., Lupu, C., Radnoti, G., de Rosnay, P., Rozum, I., Vamborg, F., Villaume, S., and Thépaut, J.-N.: The ERA5 Global Reanalysis, Q. J. Roy. Meteor. Soc., 146, 730, 19992049, https://doi.org/10.1002/qj.3803, 2020.

Hill, A. A., Dobbie, S., and Yin, Y.: The impact of aerosols on nonprecipitating marine stratocumulus. Model description and prediction of the indirect effect, Q. J. Roy. Meteor. Soc., 134, 1143 1154, https://doi.org/10.1002/qj.278, 2008.

Hintze, J. L. and Nelson, R. D.: Violin Plots: A Box Plot-Density Trace Synergism, Am. Stat., 52, 181-184, 1998.

Jiang, H., Feingold, G., and Sorooshian, A.: Effect of aerosol on the susceptibility and efficiency of precipitation in trade cumulus clouds, J. Atmos. Sci., 67, 3525-3540, 2010.

Jung, E., Albrecht, B. A., Sorooshian, A., Zuidema, P., and Jonsson, H. H.: Precipitation susceptibility in marine stratocumulus and shallow cumulus from airborne measurements, Atmos. Chem. Phys., 16, 11395-11413, https://doi.org/10.5194/acp-1611395-2016, 2016.

Khairoutdinov, M. and Kogan, Y.: A new cloud physics parameterization in a large-eddy simulation model of marine stratocumulus, Mon. Weather Rev., 128, 229-243, 2000.

King, W. D., Parkin, D. A., and Handsworth, R. J.: A hot-wire liquid water device having fully calculable response characteristics, J. Appl. Meteorol., 17, 1809-1813, https://doi.org/10.1175/15200450(1978)017<1809:AHWLWD>2.0.CO;2, 1978.

Klein, S. A. and Hartmann, D. L.: The seasonal cycle of low stratiform clouds, J. Climate, 6, 1587-1606, 1993.

Köhler, M., Ahlgrimm, M., and Beljaars, A.: Unified treatment of dry convective and stratocumulus-topped boundary layers in the ECMWF model, Q. J. Roy. Meteor. Soc., 137, 43-57, 2011.

Kubar, T. L., Hartmann, D. L., and Wood, R.: Understanding the importance of microphysics and macrophysics for warm rain in marine low clouds. Part I: Satellite observations, J. Atmos. Sci. 66, 2953-2972, 2009.

Lance, S., Brock, C. A., Rogers, D., and Gordon, J. A.: Water droplet calibration of the Cloud Droplet Probe (CDP) and in-flight performance in liquid, ice and mixed-phase clouds during ARCPAC, Atmos. Meas. Tech., 3, 1683-1706, https://doi.org/10.5194/amt-3-1683-2010, 2010.

Lawrence, M. G.: The relationship between relative humidity and the dewpoint temperature in moist air: A simple conversion and applications, B. Am. Meteorol. Soc., 86, 225-233, 2005.

Lawson, R. P., Stewart, R. E., and Angus, L. J.: Observations and numerical simulations of the origin and development of very large snowflakes, J. Atmos. Sci., 55, 3209-3229, 1998.

Lawson, R. P., O'Connor, D., Zmarzly, P., Weaver, K., Baker, B. A., Mo, Q., and Jonsson, H.: The 2D-S (Stereo) probe: Design and preliminary tests of a new airborne, high-speed, high-resolution imaging probe, J. Atmos. Ocean. Tech., 23, 1462-1477, 2006.

LeBlanc, S. E., Redemann, J., Flynn, C., Pistone, K., Kacenelenbogen, M., Segal-Rosenheimer, M., Shinozuka, Y., Dunagan, S., Dahlgren, R. P., Meyer, K., Podolske, J., Howell, S. G., Freitag, S., Small-Griswold, J., Holben, B., Diamond, M., Wood, R., Formenti, P., Piketh, S., Maggs-Kölling, G., Gerber, M., and Namwoonde, A.: Above-cloud aerosol optical depth from airborne observations in the southeast Atlantic, Atmos. Chem. Phys., 20, 1565-1590, https://doi.org/10.5194/acp-20-1565-2020, 2020.

Mardi, A. H., Dadashazar, H., MacDonald, A. B., Crosbie, E., Coggon, M. M., Aghdam, M. A., Woods, R. K., Jonsson, H. H., Flagan, R. C., Seinfeld, J. H., and Sorooshian, A.: Effects of Biomass Burning on Stratocumulus Droplet Characteristics, Drizzle Rate, and Composition, J. Geophys. Res.-Atmos., 124 12301-12318, https://doi.org/10.1029/2019jd031159, 2019.

Mauger, G. S. and Norris, J. R.: Meteorological bias in satellite estimates of aerosol-cloud relationships, Geophys. Res. Lett., 34, L16824, https://doi.org/10.1029/2007GL029952, 2007.

McComiskey, A. and Feingold, G.: The scale problem in quantifying aerosol indirect effects, Atmos. Chem. Phys., 12, 1031-1049, https://doi.org/10.5194/acp-12-1031-2012, 2012.

McFarquhar, G. M., Finlon, J. A., Stechman, D. M., Wu, W., Jackson, R. C., and Freer, M.: University of Illinois/Oklahoma Optical Array Probe (OAP) Processing Software, Zenodo [code], https://doi.org/10.5281/zenodo.1285969, 2018.

Morrison, H. and Gettelman, A.: A new two-moment bulk stratiform cloud microphysics scheme in the community atmosphere model, version 3 (CAM3). Part I: Description and numerical tests, J. Climate, 21, 3642-3659, https://doi.org/10.1175/2008JCLI2105.1, 2008.

O’Brien, J. R., Poellot, M., Delene, D., McFarquhar, G., Spanu, A., Gupta, S., Detwiler, A., and Miller, R.: The Impacts of Airborne Cloud Microphysical Instrumentation Mounting Location on Measurements Made During the Observations of Aerosols and Clouds and Their Interactions (ORACLES) Project, in preparation, 2022.

ORACLES Science Team: Suite of Aerosol, Cloud, and Related Data Acquired Aboard P3 During ORACLES 2018, Version 2, NASA Ames Earth Science Project Office [data set], https://doi.org/10.5067/Suborbital/ORACLES/P3/2018_V2, 2020a.

ORACLES Science Team: Suite of Aerosol, Cloud, and Related Data Acquired Aboard P3 During ORACLES 2017, Version 2, NASA Ames Earth Science Project Office [data set], https://doi.org/10.5067/Suborbital/ORACLES/P3/2017_V2, 2020b.

ORACLES Science Team: Suite of Aerosol, Cloud, and Related Data Acquired Aboard P3 During ORACLES 2016, Version 2, NASA Ames Earth Science Project Office [data set], https://doi.org/10.5067/Suborbital/ORACLES/P3/2016_V2, 2020c.

Oreopoulos, L. and Rossow, W. B.: The cloud radiative effects of International Satellite Cloud Climatology Project weather states, J. Geophys. Res.-Atmos., 116, D12202, https://doi.org/10.1029/2010JD015472, 2011.

Painemal, D. and Zuidema, P.: Assessment of MODIS cloud effective radius and optical thickness retrievals over the Southeast Pacific with VOCALS-REx in situ 
measurements, J. Geophys. Res.-Atmos., 116, D24206, https://doi.org/10.1029/2011JD016155, 2011.

Penner, J. E., Quaas, J., Storelvmo, T., Takemura, T., Boucher, O., Guo, H., Kirkevåg, A., Kristjánsson, J. E., and Seland, Ø.: Model intercomparison of indirect aerosol effects, Atmos. Chem. Phys., 6, 3391-3405, https://doi.org/10.5194/acp-6-3391-2006, 2006.

Pennypacker, S., Diamond, M., and Wood, R.: Ultra-clean and smoky marine boundary layers frequently occur in the same season over the southeast Atlantic, Atmos. Chem. Phys., 20, 23412351, https://doi.org/10.5194/acp-20-2341-2020, 2020.

Pistone, K., Redemann, J., Doherty, S., Zuidema, P., Burton, S., Cairns, B., Cochrane, S., Ferrare, R., Flynn, C., Freitag, S., Howell, S. G., Kacenelenbogen, M., LeBlanc, S., Liu, X., Schmidt, K. S., Sedlacek III, A. J., Segal-Rozenhaimer, M., Shinozuka, Y., Stamnes, S., van Diedenhoven, B., Van Harten, G., and Xu, F.: Intercomparison of biomass burning aerosol optical properties from in situ and remote-sensing instruments in ORACLES-2016, Atmos. Chem. Phys., 19, 9181-9208, https://doi.org/10.5194/acp-19-9181-2019, 2019.

Pistone, K., Zuidema, P., Wood, R., Diamond, M., da Silva, A. M., Ferrada, G., Saide, P. E., Ueyama, R., Ryoo, J.-M., Pfister, L., Podolske, J., Noone, D., Bennett, R., Stith, E., Carmichael, G., Redemann, J., Flynn, C., LeBlanc, S., Segal-Rozenhaimer, M., and Shinozuka, Y.: Exploring the elevated water vapor signal associated with the free tropospheric biomass burning plume over the southeast Atlantic Ocean, Atmos. Chem. Phys., 21, 96439668, https://doi.org/10.5194/acp-21-9643-2021, 2021.

Platnick, S. and Twomey, S.: Determining the susceptibility of cloud albedo to changes in droplet concentration with the advanced very high resolution radiometer, J. Appl. Meteor., 33, 334-346, 1994.

Possner, A., Eastman, R., Bender, F., and Glassmeier, F.: Deconvolution of boundary layer depth and aerosol constraints on cloud water path in subtropical stratocumulus decks, Atmos. Chem. Phys., 20, 3609-3621, https://doi.org/10.5194/acp20-3609-2020, 2020.

Quaas, J., Arola, A., Cairns, B., Christensen, M., Deneke, H., Ekman, A. M. L., Feingold, G., Fridlind, A., Gryspeerdt, E., Hasekamp, O., Li, Z., Lipponen, A., Ma, P.-L., Mülmenstädt, J., Nenes, A., Penner, J. E., Rosenfeld, D., Schrödner, R., Sinclair, K., Sourdeval, O., Stier, P., Tesche, M., van Diedenhoven, B., and Wendisch, M.: Constraining the Twomey effect from satellite observations: issues and perspectives, Atmos. Chem. Phys., 20, 15079-15099, https://doi.org/10.5194/acp-20-150792020, 2020.

Rao S., Dey S.: Consistent signal of aerosol indirect and semidirect effect on water clouds in the oceanic regions adjacent to the Indian subcontinent, Atmos. Res., 232, 104677, https://doi.org/10.1016/j.atmosres.2019.104677, 2020.

Redemann, J., Wood, R., Zuidema, P., Doherty, S. J., Luna, B., LeBlanc, S. E., Diamond, M. S., Shinozuka, Y., Chang, I. Y., Ueyama, R., Pfister, L., Ryoo, J.-M., Dobracki, A. N., da Silva, A. M., Longo, K. M., Kacenelenbogen, M. S., Flynn, C. J., Pistone, K., Knox, N. M., Piketh, S. J., Haywood, J. M., Formenti, P., Mallet, M., Stier, P., Ackerman, A. S., Bauer, S. E., Fridlind, A. M., Carmichael, G. R., Saide, P. E., Ferrada, G. A., Howell, S. G., Freitag, S., Cairns, B., Holben, B. N., Knobelspiesse, K. D., Tanelli, S., L'Ecuyer, T. S., Dzambo, A. M., Sy, O. O., McFarquhar, G. M., Poellot, M. R., Gupta, S., O’Brien, J. R.,
Nenes, A., Kacarab, M., Wong, J. P. S., Small-Griswold, J. D., Thornhill, K. L., Noone, D., Podolske, J. R., Schmidt, K. S., Pilewskie, P., Chen, H., Cochrane, S. P., Sedlacek, A. J., Lang, T. J., Stith, E., Segal-Rozenhaimer, M., Ferrare, R. A., Burton, S. P., Hostetler, C. A., Diner, D. J., Seidel, F. C., Platnick, S. E., Myers, J. S., Meyer, K. G., Spangenberg, D. A., Maring, H., and Gao, L.: An overview of the ORACLES (ObseRvations of Aerosols above CLouds and their intEractionS) project: aerosolcloud-radiation interactions in the southeast Atlantic basin, Atmos. Chem. Phys., 21, 1507-1563, https://doi.org/10.5194/acp21-1507-2021, 2021.

Rogers, R. R. and Yau, M. K.: A Short Course in Cloud Physics, 3rd edn., International Series in Natural Philosophy, ButterworthHeinemann, 290 pp., ISBN 9780750632157, 1989.

Sakaeda, N., Wood, R., and Rasch, P. J.: Direct and semidirect aerosol effects of southern African biomass burning aerosol, J. Geophys. Res., 116, D12205, https://doi.org/10.1029/2010JD015540, 2011.

Small, J. D., Chuang, P. Y., Feingold, G., and Jiang, H.: Can aerosol decrease cloud lifetime?, Geophys. Res. Lett., 36, 16806, https://doi.org/10.1029/2009GL038888, 2009.

Sorooshian, A., Feingold, G., Lebsock, M. D., Jiang, H., and Stephens, G. L.: On the precipitation susceptibility of clouds to aerosol perturbations, Geophys. Res. Lett., 36, L13803, https://doi.org/10.1029/2009GL038993, 2009.

Sorooshian, A., Feingold, G., Lebsock, M. D., Jiang, H., and Stephens, G.: Deconstructing the precipitation susceptibility construct: improving methodology for aerosol cloud precipitation studies, J. Geophys. Res., 115, D17201, https://doi.org/10.1029/2009JD013426, 2010.

Sorooshian, A., Anderson, B., Bauer, S. E., Braun, R. A., Cairns, B., Crosbie, E., Dadashazar, H., Diskin, G., Ferrare, R., Flagan, R. C., Hair, J., Hostetler, C., Jonsson, H. H., Kleb, M. M., Liu, H. Y., MacDonald, A. B., McComiskey, A., Moore, R., Painemal, D., Russell, L. M., Seinfeld, J. H., Shook, M., Smith, W. L., Thornhill, K., Tselioudis, G., Wang, H. L., Zeng, X. B., Zhang, B., Ziemba, L., and Zuidema, P.: Aerosol-CloudMeteorology Interaction Airborne Field Investigations: Using Lessons Learned from the US West Coast in the Design of ACTIVATE off the US East Coast, B. Am. Meteorol. Soc., 100, 15111528, https://doi.org/10.1175/Bams-D-18-0100.1, 2019.

Stephens, G. L., L'Ecuyer, T., Forbes, R., Gettlemen, A., Golaz, J. C., Bodas-Salcedo, A., Suzuki, K., Gabriel, P., and Haynes, J.: Dreary state of precipitation in global models, J. Geophys. Res.Atmos., 115, D24211, https://doi.org/10.1029/2010jd014532, 2010.

Terai, C. R., Wood, R., Leon, D. C., and Zuidema, P.: Does precipitation susceptibility vary with increasing cloud thickness in marine stratocumulus?, Atmos. Chem. Phys., 12, 4567-4583, https://doi.org/10.5194/acp-12-4567-2012, 2012.

Toll, V., Christensen, M., Quaas, J., and Bellouin, N.: Weak average liquid-cloud-water response to anthropogenic aerosols, Nature, 572, 51-55, https://doi.org/10.1038/s41586-019-1423-9, 2019.

Trenberth, K. and Fasullo, J.: Global warming due to increasing absorbed solar radiation, Geophys. Res. Lett., 36, L07706, https://doi.org/10.1029/2009GL037527, 2009.

Twomey, S.: Pollution and the Planetary Albedo, Atmos. Environ., 8, 1251-1256, 1974. 
Twomey, S.: The influence of pollution on the shortwave albedo of clouds, J. Atmos. Sci., 34, 1149-1152, 1977.

Wilcox, E. M.: Stratocumulus cloud thickening beneath layers of absorbing smoke aerosol, Atmos. Chem. Phys., 10, 1176911777, https://doi.org/10.5194/acp-10-11769-2010, 2010.

Wood, R.: Stratocumulus Clouds, Mon. Weather Rev., 140, 2373 2423, https://doi.org/10.1175/MWR-D-11-00121.1, 2012.

Wood, R. and Bretherton, C. S.: On the relationship between stratiform low cloud cover and lower-tropospheric stability, J. Climate, 19, 6425-6432, 2006.

Wood, R. and Hartmann, D. L.: Spatial variability of liquid water path in marine low cloud: the importance of mesoscale cellular convection, J. Climate, 19, 1748-1764, 2006.

Wood, R., Kubar, T. L., and Hartmann, D. L.: Understanding the Importance of Microphysics and Macrophysics for Warm Rain in Marine Low Clouds. Part II: Heuristic Models of Rain Formation, J. Atmos. Sci., 66, 2973-2990, https://doi.org/10.1175/2009JAS3072.1, 2009.
Xue, H. and Feingold, G.: Large eddy simulations of trade wind cumuli: investigation of aerosol indirect effects, J. Atmos. Sci., 63, 1605-1622, 2006.

Zhang, Z. and Platnick, S.: An assessment of differences between cloud effective particle radius retrievals for marine water clouds from three MODIS spectral bands, J. Geophys. Res.-Atmos., 116, D20215, https://doi.org/10.1029/2011JD016216, 2011.

Zuidema, P., Redemann, J., Haywood, J., Wood, R., Piketh, S., Hipondoka, M. and Formenti, P.: Smoke and Clouds above the Southeast Atlantic: Upcoming Field Campaigns Probe Absorbing Aerosol's Impact on Climate, B. Am. Meteorol. Soc., 97, 1131-1135, https://doi.org/10.1175/BAMS-D-15-00082.1, 2016. 